\title{
Bayesian multi-model projection of irrigation requirement and water use efficiency in three typical rice plantation region of China based on CMIP5
}

Weiguang Wang,b*, Yimin Ding ${ }^{\mathrm{a}}$, Quanxi Shao ${ }^{\mathrm{c}}$, Junzeng Xua ${ }^{\mathrm{a}}$, Xiyun Jiao ${ }^{\mathrm{a}}$, Yufeng Luo ${ }^{\mathrm{d}}$, Zhongbo $\mathrm{Yu}^{\mathrm{a}, \mathrm{b}}$

a. State Key Laboratory of Hydrology-Water Resources and Hydraulic Engineering, Hohai University, Nanjing 210098, China

b. College of Water Resources and Hydrology, Hohai University, Nanjing 210098, China

c. CSIRO Computational Informatics, Private Bag 5, Wembley, WA 6913, Australia

d. State Key Laboratory of Water Resources and Hydropower Engineering Science, Wuhan University, Wuhan 430072, China

*Corresponding author:

Dr. Weiguang Wang

State Key Laboratory of Hydrology-Water Resources and Hydraulic Engineering Hohai University, Nanjing 210098, China

Tel +86-25-83786786

Fax: +86-25-83786606

Email: wangweiguang006@126.com 


\section{Abstract}

Rice growth is significantly influenced by the ongoing climatic change and subjected to water shortages. Projection on the changes of rice productivity growth and water resources utilization under future climates is of great importance for food security and water resources sustainable management. Climate model outputs in combination with physical-based crop model is an effective way to modeling the crop productivity and water consumption response, but uncertainties associated with climate models remain a major challenge. In this study, we introduce a Bayesian model averaging (BMA) method to provide the multi-model ensemble projections by merging 4 climate models under four emissions scenarios (RCP2.6, RCP4.5, RCP6.0 and RCP8.5) from phase five of the Coupled Model Intercomparsion Project (CMIP5). The comprehensive investigation on how the rice yield, water consumption (ET), irrigation water requirement (IR), water use efficiency (WUE) and irrigation water use efficiency (IWUE) response to future climate scenarios with taking account of $\mathrm{CO}_{2}$ concentration enrichment in three typical sites (Kunshan and Nanjing in the Yangtze River Basin, and Kaifeng in the Yellow River Basin) in rice plantation region of China was conducted by driving a well-validated rice crop model ORYAZ2000 with merging multimodel ensemble projected climate outputs. There are some obvious uncertainties for climate models projections in climatic variables with wide model spread, especially for solar radiation and wind speed. The BMA method is most competent to produce the ensemble with the lowest bias in comparison with simple model averaging (SA) method and individual climate model. In despite of the distinct response of the growth duration to future climate change for the three stations, the rice yield would be reduced significantly under the climate warming. IR would present more remarkable increase compared with the ET, especially for Nanjing and Kunshan stations, due to the decrease in precipitation during the rice growth period. The significant reduction in rice 
production together with enlargement in ET and IR, resulted in the generally depressed the WUE and IWUE. In addition, despite that the $\mathrm{CO}_{2}$ fertilization effect cannot compensate the negative effect of temperature increase, the increase of $\mathrm{CO}_{2}$ concentration can promote the overall level of yield and consequently improve the water use efficiencies of rice.

Keywords: Climate change; Multi-model ensemble; Water use efficiency; Bayesian model averaging (BMA); Uncertainties

\section{Introduction}

Mainly characterized by global warming, with that the clear warming occurred in recent decades and an unambiguously continual increase in global mean temperature expected in this century, climate change has affect dramatically on social and natural systems, and thus cause broad public concerns [IPCC, 2013; Huntington, 2006; Wang et al., 2014a]. Among the suffering to climate change, the most sensitive ones are usually considered to be crop production and related water resources utilization [Peng et al., 2004; Huntington, 2006; Tao et al., 2011, 2013]. In despite of the growing importance of industry, agriculture still has the central role in ensuring the food security and welfare of people across the world, which is especially true in China [Piao et al., 2010]. With this respect, recently, a considerable concern has been paid to explore the effects of climate change on agriculture, particularly the growth, development and productivity of the crop [e.g., Brumbelow and Georgakakos, 2001; Peng et al., 2004; Easterling et al., 2007; Tao et al., 2008; Challinor and Wheeler, 2008; Mo et al., 2009; Lobell et al., 2011; Luo et al., 2015]. In China, the benefits of climate change for crop growth and production, including longer growing seasons [Xiong et al., 2007], increasing atmospheric $\mathrm{CO}_{2}$ [Liu et al., 2010], warmer nighttime temperatures and higher 
precipitation [Thomoson et al., 2006], and the adverse impacts, such as reduced water availability [Bouman et al., 2007], greater water demand [Piao et al., 2010], and more frequent extreme high temperature [Shen et al., 2011], have been documented based on historical long-term filed experiments and crop model simulation, respectively [Wang et al., 2014a].

In fact, apart from the crop production, the ground and surface water supply, irrigation and water resources use are also affected by climate change due to the ongoing intensification of regional hydrological cycles with the alterations of precipitation, runoff, infiltration, groundwater flow, evapotranspiration, and soil moisture in many parts of the world during past century [Alan et al., 2003; Huntington, 2006]. Therefore, compared with crop production, although the assessment on response of water resources use in agriculture, such as crop water consumption, irrigation water requirement and efficiency to climate change started later, attempts to explore how the past climate variability has impacted the irrigation water requirements and water use efficiencies with experiment and modelling approach have also been widely conducted, especially during recent decades [e.g., Döll, 2002; De Silva et al., 2007; Fischer et al., 2007; Cong et al., 2008; Wang et al., 2013;Yang et al., 2013; Luo et al., 2015]. In fact, providing the adaptation, the key factor that will shape the future severity of climate change impacts on food production and water resources management, is the ultimate goal of climate change impact assessment. Hence, reliable estimation of the evolution direction of water balance and the crop production is of increasing importance in assessing the effects of climate change, which becomes more pronounced [Bates et al., 2008]. In consequence, being the centralized reflection of interaction effect between ecophysiological processes and climatic regime, future production efficiency and water use efficiency projections by means of climate models are more highly required than historical change analysis.

Substantial progress in both global and regional modeling at medium to high resolution as 
well as the downscaling methods have provided the basis for an increasing number of studies that attempt to model the effect of future climate change. Under the support of the Intergovernmental Panel on Climate Change (IPCC) Fifth Assessment Report [IPCC, 2013] with the representative concentration pathways (RCPs), over 50 modeling groups around the world conducted climate change simulation, which is also known as Phase 5 of the Coupled Model Intercomparsion Project (CMIP5) experiment [Taylor et al., 2012]. Meanwhile, driving ecophysiological and hydrological process-based crop model with the future climate information from global climate models (GCMs) is currently considered as the most prevalent method to characterize the response of crop yield and water resources utilization [Wang et al., 2014a]. Some GCM models can fully meet the requirement of the relevant meteorological variables driving the crop models, hence offering opportunities for us to conduct the multi-model ensemble analysis of the simulation and projection of future crop growth processes and water use efficiency. Unfortunately, the future projection is always subject to large uncertainties derived from the different performances of GCM ensembles in describing the future local climatic information, having quite a wide range [Meehl et al., 2007; Asseng et al., 2013].

Merging multiple algorithms can be effectively used to alleviate the uncertainties from the distinction of single model. The traditional simple multi-model averaging method is widely used and proved to perform better than any individual model for estimating climatic and hydrologic variables [Raftery et al., 1997, 2005; Madigan et al., 1999; Houghton, 2001; Duan and Phillips, 2010]. Recently, a more complicated merging method, the Bayesian model averaging (BMA) approach is proposed for model evaluation and multi-model averaging with a systematic consideration of model uncertainty [Min et al., 2004, 2005; Min and Hense, 2006]. As a way to combine different models, BMA is rather a promising method for calibrating multi-model ensemble 
modeling and forecasting in climatic impact research. For example, its application to global mean surface air temperature (SAT) changes is shown from multi Atmosphere-Ocean General Circulation Model (AOGCM) [IPCC, 2007]. BMA is adaptive in the sense that recent realizations of the forecast system are employed to conduct the calibration [Yang et al., 2012]. As a method of combining forecasts from different sources into a consensus probability density function (PDF), an ensemble analog to consensus forecasting methods applied to deterministic forecasts from different sources [Vislocky and Fritsch, 1995; Krishnamurti et al., 1999; Wang et al., 2014b], BMA naturally applies ensemble system to a set of discrete models (such as the Canadian ensemble system). The overall forecast PDF is the weighted average of individual forecast PDFs in BMA. As the estimated posterior model probabilities, the weights can reflect the forecast skill of individual models in the training period. Meanwhile, the weights can provide a basis for selecting ensemble members with only little loss by remove the ensemble number with small weights [Raftery et al., 2005; Wilson et al., 2007]. This is a valuable strategy, given that the computational cost of running ensembles is more affordable nowadays. Due to the pronounced advantages, various BMA methods are increasingly employed in climate change studies including detection, attribution and climate model evaluation [e.g., Min et al., 2004, 2005; Min and Hense, 2006], weather and hydrology predictions [e.g., Hoeting et al., 1999; Duan et al., 2007; Duan and Philips, 2010; Wu et al., 2012], future projections of hydrometeorological variables and climate extremes [e.g., Yang et al., 2011, 2012; Wang et al., 2014b; Xing et al., 2014] as well as multi-sources data fusion for improving ecological parameter estimation [e.g., Yao et al., 2014].

As the most important food in the world, rice serves as a basic staple for nearly half of the world's population [Peng et al., 1995]. This is especially true in China, where rice is the staple food for more than $65 \%$ of Chinese population [State Environmental Protection Administration, 
2003]. Although China has the second largest area of rice cultivation, contributing $19 \%$ of the world rice, China has the highest rice production, representing $29 \%$ of the total world rice production $[F A O, 2010]$, as well as more than $40 \%$ of the national cereals yield of China [National Bureau of Statistics of China, 2009]. Unfortunately, suffered from ongoing climate change and thus the irrigation shortage recently, being crucial for global food security, rice production under future climates is facing a big challenges in China and rest of the world [Peng, 2004; Tao et al., 2008; Godfray et al., 2010; Piao et al., 2010; Li et al., 2015]. Therefore, there is a growing need to investigate and understand the vulnerability of rice production, irrigation water requirement and water use efficiency in the future based on the state-of-art climate models and ensemble approaches in individual and typical regions. Extensive studies have attempt to assess climate impacts on crop growth and yields in the future using process-based crop models, driven by climate change scenarios output from global climate model or regional climate model [e.g., Aggarwal and Mall, 2002; Parry et al., 2004; Yao et al., 2007; Xiong et al., 2008, 2009; Tao et al., 2008, Shen et al., 2011; Wang et al., 2014a]. However, most of the aforementioned efforts focused only on the response of crop yield to climate change without consideration of changes in irrigation requirement and water use efficiency in the future under the global warming conditions. Even that in the available literature on climate impact research involved the irrigation and water use efficiency [e.g., Liu et al, 2004; Wang et al., 2014a; Luo et al., 2015], most of them are based on simple assumed climatic increment scenario or individual GCM. Although more practice, overreliance on a single GCM or arithmetic ensemble mean will lead to more uncertainties and thus lead to inappropriate planning or adaptation response. Hence, in-depth studies on simulating ecophysiological and hydrological response of rice with considering uncertainties from different GCMs are imperative, motivating our present research. In this study, based on 4 climate models and four pathways 
(RCP2.6, RCP4.5, RCP6.0 and RCP8.5) from the CMIP5, we offered the comprehensive investigation on the response of rice yield, water consumption and irrigation requirement as well as water use efficiency to future climate scenarios of 21 st century using multi-model ensemble projection with introducing BMA approach in China. For this, ORYZA2000, a widely used rice crop model, was evaluated against field experiments at three typical sites of rice plantation area in different eco-climatic area in China.

\section{Materials and methods}

\subsection{Study sites and field experiment}

In this study, with different geographic and climatological conditions, three representative rice ecological stations, i.e., Kaifeng, Nanjing and Kunshan, were selected to implement the bayesian multi-model projection of irrigation demand and water use efficiency. Kaifeng $\left(34^{\circ} 82^{\prime} \mathrm{N}, 114^{\circ} 51^{\prime} \mathrm{E}\right.$; $69.0 \mathrm{~m}$ a.s.1.) belongs to the middle of the Yellow River and is distributed in the southern bank of the river, while Nanjing $\left(32^{\circ} 00^{\prime} \mathrm{N}, 118^{\circ} 28^{\prime} \mathrm{E} ; 7.1 \mathrm{~m}\right.$ a.s.1. $)$ and Kunshan $\left(31^{\circ} 23^{\prime} \mathrm{N}, 120^{\circ} 58^{\prime} \mathrm{E} ; 17.5\right.$ $m$ a.s.l.) are located in the middle and lower reaches of the Yangtze River Basin (Figure 1). All the three sites are distributed in the Middle and South China, where warm climate and abundant precipitation under summer monsoon circulation is suitable for the long term growth of rice. With paddy field distributing from place to place, $90 \%$ of the total area of rice growing in China is located in this famous rice plantation region [Yao et al., 2007].

Observed data on rice phenological stages, leaf area index (LAI), biomass, grain yield, crop water use and soil water dynamic from three experiment stations were used to calibrate and validate the ORYZA2000. The experiment data of Kaifeng and Nanjing stations to run the ORYZA2000 crop model were shared freely to public by the International Rice Research Institute (IRRI) from the website http://www.knowledgebank.irri.org/oryza2000/ [Cabangon et al., 2003; Feng et al., 
2007]. Therefore, the field experiment was only conducted at Kunshan Irrigation and Drainage Experiment Station in Jiangsu Province. Although the crop growth and irrigation experiment in Kunshan has been continuously carried out for ten years, and the applicability of ORYZA2000 has been identified with experiment data in 2007 and 2008 (see Wang et al., 2014a), to reflect the latest crop growth, climate and management conditions, the up to date experiment data in 2011 and 2012 was used to test the ORYZA2000 in this study.

Soil in the experimental site was classified as dark-yellow hydromorphic paddy soil, representing the typical soil type in this region. The soil texture in the plowed layer was clay. Rice seedlings were transplanted to the paddy fields on June 29 and harvested on October 25, 2011, and on June 29 and harvested on October 24, 2012. With the same condition of rice varieties, transplanting, density, plant protection, fertility, medication and other technical measures, three repeat treatments were set in three experimental fields with the field area of about $150 \mathrm{~m}^{2}(20$ $\mathrm{m} \times 7.5 \mathrm{~m})$. Weed, pests and diseases were well controlled using recommended practices. All treatments received the fertilizer applications for local farmer's fertilization practice (details see $X u$ et al., 2012). The information of dates of emergence, transplanting, panicle initiation, and physiological maturity during all the experiment period were recorded. During the growing season, crop samples were collected, and the LAI, the dry weights of green leaves, the brown/yellow leaves, stems, and panicles were measured. Soil moisture and ponding water layer depth were measured daily by time-domain reflectometry equipment (TDR, Soil moisture, USA) and vertical ruler, respectively. Water volumes for irrigation were routinely recorded using water meters installed on the pipes at the outlet for each plot. Drainage was calculated by measuring water depths before and after the drainage. Grain yield was determined for each plot from the smaller crop sample at maturity. Meanwhile, an automatic meteorological station (ICT, Australia) was placed at the 
experiment field to collect daily meteorological data including precipitation, vapor pressure, wind speed, temperature, relative humidity and radiation.

\subsection{ORYZA2000 model}

ORYZA2000 is an advanced, explanatory and dynamic eco-physiological rice growth simulation model of the 'School of De Wit' [Bouman et al., 1996; van Ittersum et al., 2003; Yadav et al., 2011]. The ORYZA2000 model can simulate the growth processes, development and water balance of rice under potential production in both water-limited and nitrogen-limited environments. It is assumed that, in all the production situation, the rice is well protected against disease, pests and weeds and that no reductions in yield take place [Bouman and van Laar, 2006]. The ORYZA2000 model has been widely employed in various studies with respect to nitrogen effect [e.g., Bouman and van Laar, 2006], water management optimization [e.g., Feng et al., 2007; Yadav et al., 2011] and climate change impact assessment [e.g., Zhang et al., 2008; Shen et al., 2011; Karim et al., 2012]. The performances of ORYZA2000 model were also found to be satisfactory and competent through the validations under different water regimes, irrigation practices, and various levels of nitrogen fertilization with time step of 1-day [Boling et al., 2007; Feng et al., 2007]. The model requires inputs of weather data, soil properties, management practices, and crop parameters. Most of the crop parameters can be set as default values. However, the genetic parameters reflecting rice heredity and variety characteristics, e.g., development rates, partitioning factors, relative leaf growth rate, specific leaf area, leaf death rate and fraction of stem reserves need to be calibrated based on the field experiments. The calibration and validation data used for ORYZA2000 model in this study includes total crop biomass, biomass of panicles, biomass of stems, biomass of green leaves and the leaf area index. The irrigation water requirement, here means water consumption in filed, was computed by the subroutine IRRIG of the model, which was established based on the 
water balance among precipitation, irrigation water requirement, percolation, evapotranspiration and seepage. The subroutine IRRIG computes the daily amount of irrigation (i.e., the daily irrigation water requirement) as a function of user-specified criteria. The five irrigation criteria are rained, irrigation supplied as input data, irrigation at critical ponded soil water depth, irrigation at critical soil-water tension, irrigation at critical soil water content and irrigation at a certain number of days after disappearance of ponded water. In this study, the daily amount of irrigation water requirement was determined by the depth of ponded water. $75 \mathrm{~mm}$ irrigation amount is given when the ponded water depth drops below the threshold $10 \mathrm{~mm}$. A detailed description of the model and program model can be found in Bouman et al. [2001] and Bouman and van Laar [2006], and the key modules for potential and water-limited conditions are well explained in these literatures [e.g., Arora, 2006; Boling et al., 2007; Yadav et al., 2011].

\subsection{Bayesian model Averaging method}

\subsubsection{General framework}

As a standard statistical procedure for combining predictive distributions from different sources, Bayesian model averaging method (BMA) has recently been proposed as a way of correcting underdispersion in ensembles forecasts [Raftery et al., 2005; Min and Hense, 2006; Xing et al., 2014; Wang et al., 2014b], offering an approach of combining statistical models and concurrently calibrating them using a training dataset. The BMA predictive probability density function (PDF) for future climatic variables of interest is a weighted average of PDFs centered on the individual bias-corrected forecasts [Raftery et al., 1997; Hoeting et al., 1999; Duan and Philips, 2010; Wu et al., 2012]. The BMA method can improve the forecasts by adjusting the predictive PDF to obtain a good fit to the local observations. The combined forecast PDF of a variable $y$ is 


$$
p\left(y \mid y^{T}\right)=\sum_{k=1}^{K} p\left(y \mid M_{k}, y^{T}\right) p\left(M_{k} \mid y^{T}\right)
$$

Where $p\left(y \mid M_{k}, y^{T}\right)$, estimated from the training data, is the predictive PDF based on model $M_{k}$ alone; $k$ is the number of models being combined, equaling to 4 in the current study. $p\left(M_{k} \mid y^{T}\right)$ denotes the posterior probability that model $M_{k}$ is correct given the training data and is computed with the help of Bayes' theory

$$
p\left(M_{k} \mid y^{T}\right)=\frac{p\left(y^{T} \mid M_{k}\right) p\left(M_{k}\right)}{\sum_{l=1}^{k} p\left(y^{T} \mid M_{l}\right) p\left(M_{l}\right)}
$$

Taking the consideration of the application of BMA to bias-corrected forecasts from the $k$ models, equation (1) can be expressed as

$$
p\left(y \mid f_{1} \cdots \cdots f_{k}, y^{T}\right)=\sum_{k=1}^{k} \omega_{k} p_{k}\left(y \mid f_{k}, y^{T}\right)
$$

Where $\omega_{k}=p\left(M_{k} \mid y^{T}\right)$ is the BMA weight for model $k$ computed from the training dataset, representing the relative performance of model $k$ in the training period. The weights $\omega_{k}$ add up to 1 . Meanwhile, the conditional probabilities $p_{k}\left(y \mid\left(f_{k}, y^{T}\right)\right.$ may be interpreted as the conditional PDF of $y$ given $f_{k}$, given that model $k$ has been selected (or is the "best" model or member), based on the training data. Moreover, these conditional PDFs are assumed to be normally distributed as

$$
y \mid\left(f_{k}, y^{T}\right) \sim N\left(a_{k}+b_{k} y_{k}, \sigma^{2}\right)
$$

Where the coefficient $a_{k}$ and $b_{k}$ are estimated from the bias-correction procedures described above, meaning that the BMA predictive distributions becomes a weighted sum of normal distributions with equal variances but centered at the bias-corrected forecast, which can also be get from BMA distribution with the aid of the conditional expectation of $y$ given the forecast 


$$
E\left[y \mid\left(f_{1} \cdots \cdots f_{k}, y^{T}\right)\right]=\sum_{k=1}^{k} \omega_{k}\left(a_{k}+b_{k} f_{k}\right)
$$

This forecast would be expected to be more skillful than no matter the ensemble mean or any one member, since the forecasted results are determined from an ensemble distribution that has had first and second moments bias-corrected by recent verification data for all the ensemble members. Generally speaking, the combined result by BMA is an essentially "intelligent" consensus forecast weighted by the recent performance results for the component model [Wang et al., 2014b].

\subsubsection{Estimation of model weights and variance}

The maximum likelihood is used to estimate the BMA weights and variance [Raftery et al., 2005] based on the training data. Being considered as a function of the parameter, the likelihood function is defined as the probability of the training data for the parameters to be estimated. The weights and variance are determined in order to maximize the likelihood function, that is, the value of the parameter vector under which the observed data were most likely to have been observed. The algorithm employed to calculate BMA weights and variance is termed as the expectation maximization (EM) algorithm [Dempster et al., 1977; McLachlan and Krishnan, 1997]. The method is iterative and converges to a local maximum of the likelihood. More complete explanation of the BMA method and the EM algorithm can be found in Raftery et al. [2005] and McLachlan and Krishnan [1997], respectively. The value of the variance is related to the total pooled error variance for all the models of the training dataset [Xing et al., 2014].

\subsection{Projection of future climatic variables}

The future climate projections were acquired from four GCMs including BCC-CSM1.1 (m), MIROC-ESM-CHEM, GFDL-ESM2M and HadGEM2-ES (see Table 1), participating in the CMIP5 experiment [Taylor et al., 2012]. These four models were selected since they can fully meet 
the data requirement to force the ORYZA2000 crop model and were widely applied in climate impact studies with favorable feasibility in China [e.g., Guo et al., 2015; Yin et al., 2015]. This set of projection spans the entire 21 st century scenarios range leading to difference radiative forcing levels with RCP8.5 being a high emissions scenario (Radiation force rise to $8.5 \mathrm{~W} \mathrm{~m}^{-2}$ by 2100 ), RCP2.6 being a low so-called peak-and-decay scenario (Radiative force reaches a maximum near the middle of 21 st century before falling to $2.6 \mathrm{~W} \mathrm{~m}^{-2}$ ), RCP6.0 and RCP4.5 being two intermediate scenarios (Radiation force stability in $6.0 \mathrm{~W} \mathrm{~m}^{-2}$ and $2.6 \mathrm{~W} \mathrm{~m}^{-2}$ by 2100 , respectively). It should be specially noted that, to remove the systematic bias in models and transform simulated climate patterns at coarse grid to a point scale of local interesting to drive the crop model, a bias-correction method named quantile mapping (also called quantile-quantile transformation or CDF matching) continuously developed by Li et al. [2010] and Wang and Chen [2013] adjusting the distribution of GCMs outputs to make it closely representing the observed climatology by finding a transfer function between the model outputs and the observations, was applied to correct the bias in model simulation of GCMs. This method (The details see Wang and Chen, 2013) breaks the limitation of the assumption of traditional quantile-used matching method that the transfer function relating observations to model simulations remains unchanged in an altered climate, as well as avoids the problem of a negative value (e.g., for precipitation) as a result of applying the additive factor.

\subsection{Model performance}

Taylor diagrams were employed in this study to evaluate the performance of individual GCM output, the Simple Model Averaging (SA) methods and the BMA method to qualify how closely the modeled climatic variables matched the ground observations [Taylor, 2001]. As a polar-style graph, Taylor diagram summarize the three statistic index, i.e., correlation coefficient between simulations and observations (R), the root-mean-square error (RMSE), and the standard deviation 
(STD), using a single point. The radial distance from the origin reflects STD, the cosine of azimuth angle denotes $\mathrm{R}$, and the radial distance from the observed points is proportional to the RMSE difference [Yao et al., 2014]. Generally, a main criterion can be summarized that the closer a point is to the observed data, the better the fit between observed and simulated one. The Taylor diagrams are particularly beneficial in evaluating the relative accuracy of different models due to its comprehensiveness and visualizability.

\section{Results}

\subsection{ORYZA2000 model calibration and its performance in representing filed measurements}

During the simulation, although most of the parameter set in the ORYZA2000 can be set as default values, the genetic parameters reflecting rice heredity and variety characteristics, e.g., development rates, partitioning factors, relative leaf growth rate, specific leaf area, leaf death rate and fraction of stem reserves need to be calibrated based on the field experiments. Hence, with the meteorological data gained from automatic weather station built in the experiment field, two calibration programs, DRATES and PARAM, set up in the ORYZA2000 model were employed to calibrate the rice genetic parameters. The detailed values of calibrated parameters of three stations were shown in Table 2. Taking Kunshan station for example, graphical examples in measured and simulated biomass partitioning as well as the scatter plots of measured versus simulated observations are shown in Figure 2 for the calibration set (2011) and the validation set (2012). Meanwhile, Comparisons of measured and simulated LAI of the crop are shown in Figure 3. The observed processes of biomass accumulation can be captured by the calibrated ORYZA2000 model. The scatter plots of measured versus simulated total biomass show that the simulated values were within reasonable agreement with the observed ones, with the spread being generally close to the 1:1 line. The quantitative goodness-of-fit parameters (Table 3) also showed a reasonable 
relationship between observed and simulated values with slope $(\alpha)$ close to $1(0.74-0.97)$ and a relatively small intercept $(\beta)$. In addition, the regression coefficients for all growth variables ranged from 0.89 to 0.99 and were usually larger than 0.96 . The absolute root mean square error $\left(R M S E_{a}\right)$ was $0.37-0.56 \mathrm{t} \mathrm{ha}^{-1}$ with normalized root mean square error $\left(R M S E_{n}\right)$ of $6.31-19.37 \%$ for observed variables and simulated biomass of crop organ and the whole crop. Generally, all crop variables were reproduced very well in despite of some underestimation of the biomass of stems and of LAI at harvest (or at 60 days after emergence), indicating that the ORYZA2000 model can be used to simulate the effect of climate change on the local rice variety in a relative high accuracy.

\subsection{Evaluation of BMA method for merging multi-model ensemble}

None of the individual GCM model ensemble provides the best local meteorological information for all the climatic change processes. Therefore, we use BMA method to estimate the climatic variables required by the ORYZA2000 model by integrating the multi-model ensemble used in this study. In this section, the performance of BMA method for merging multi-model ensemble projections for the future change in climatic variables was evaluated based on Taylor diagrams. From the perspective of climate research, the BMA parameters can be better estimated with longer training period [Yang et al., 2012]. Following the previous BMA application studies [e.g., Yang et al., 2012; Xing et al., 2014; Wang et al., 2014b], a 40-year period (1961-2000) was used to train BMA weights for four GCM models under four representative concentration pathway scenarios, while the rest period (2001-2099) was used to generate present and future scenario of climate variables for crop model inputs in three experiment sites. Before merging the multi-model ensemble, the BMA weights are calculated by the EM algorithm. Figure 4 presents the weights of the four GCM ensembles for six crop model input climatic variables at the three experiment stations. The relative contributions of different GCM ensembles vary for different climatic variables as well 
as different experiment stations. For example, HADGEM2-ES has the highest weight for maximum temperature in three stations and MIROC-ESM-CHEM has the highest weight for precipitation in Kunshan and Nanjing stations. While GFDL-ESM2M has the highest weight for minimum temperature in Kunshan station and the highest weight for water vapor in Kaifeng station, respectively. Meanwhile, BCC-CSM1.1 (m) provides the highest contribution for solar radiation in Nanjing and Kaifeng stations, indicating its lower RMSE for solar radiation estimation compared with the other GCMs. Taking Kunshan station for example, Figure 5 displays the monthly variation of six climatic variables during the period of 2001-2005 from the observation and model simulation, permitting a visual inspection of the performance by the observations against single model ensembles with uncertainties range. Apparently, the monthly variables variations yielded by BMA method are more strongly consistent with the ground-measured values by any individual model production. Compared with water vapor, maximum and minimum temperature, precipitation, solar radiation and wind speed present wider model spread, suggesting larger uncertainties. Moreover, the performance of BMA and SA methods in three sites are also compared. For offering more intuitionistic information in evaluating the relative accuracy of models as well as the performance of ensemble merging algorithms, also taking the Kunshan station as the example, Figure 6 demonstrates the statistic results of inter-comparison of model skills with a Taylor diagram, a polarstyle graph. The overall impression of Figure 6 is that the BMA method agrees with observations that lie nearest the point marked "observed" on the $\mathrm{x}$ axis, and the BMA method has higher correlation and lower RMSE compared with the SA ensemble and individual model for all the projected climatic variables. Compared with other four climatic variables, precipitation and wind speed of GCMs show weaker capability of matching local climatic information with lower correlation and larger RMSE, even for BMA methods, only with $r$ between 0.6 and 0.7 . The SA 
method has better performance than most individual GCM in simulating the regional climate variables, except wind speed. That is why the multi-model mean was sometime used in the climate projections to reduce the errors associated with using an individual model. Nevertheless, apparently, the skill-weighted average by the Bayes factors is more superior that the arithmetic ensemble mean based on conventional statistics, especially in merging the ensembles with weak effectiveness in capture the local climatic behavior (e.g., precipitation and wind speed in the current study), confirming the applicability of BMA to projection of key input climatic variables for ORYZA2000 model.

\subsection{BMA-based projection of rice yield and water use based on CMIP5}

\subsubsection{Projection of changes in growth duration, rice yield, ET, and IR}

Under the current cultivation and agronomic management condition, rice growth duration, rice yields, water consumption (ET), irrigation water requirement (IR) with as well as without consideration $\mathrm{CO}_{2}$ fertilization effects were simulated by driving the calibrated ORYZA2000 model with BMA-based projection of future climate conditions under four RCPs. The average rice growth duration would be shortened for almost all the three stations for three future periods under four scenarios, except that under RCP8.5 scenario in 2080s period (Figure 7). Although the three stations presented the similar change patterns of growth duration, temporal and spatial differences for the numbers of shorten days can be apparently found. For Kaifeng, the maximum of 8 days and the minimum of 4 days were found to be shortened under RCP2.6 in 2080s and under RCP6.0 in 2080s, respectively. For Nanjing, the maximum of 10 days and the minimum of 4 days were found to be shortened under RCP4.5 in 2080s and under RCP6.0 in 2080s, respectively. While for Kunshan, the maximum of 6 days and the minimum of 2 days was found to be shortened under RCP4.5 in 2050s and RCP2.6 in 2020s, respectively. Moreover, it should be specially noted that 
different with that under other scenario and other stages, under RCP8.5 in 2080s, rice growth duration for all three stations increased sharply with the number ranging from 5 to14 days. Although the changing patterns of rice growth duration differ considerably, the rice yield presented almost consistent reduction for all the three stations in different stages of the 21 st century (Figure 8). That is particularly true with consideration of $\mathrm{CO}_{2}$ fertilization. Meanwhile, an increasing yield reduction behavior over time (i.e., from 2020s to 2080s) could be nearly found under four scenarios in all three stations, especially with consideration of $\mathrm{CO}_{2}$ fertilization. At Kaifeng, without consideration of $\mathrm{CO}_{2}$ fertilization, relative to that under baseline, the minimum and maximum decrease in rice yield could be found under RCP2.6 in 2020s by $-5.4 \%$ and under RCP8.5 in 2080s by $-16.6 \%$, respectively. At Nanjing, the minimum and maximum decrease in rice yield can be found under RCP2.6 in 2020s by $-6.6 \%$ and under RCP8.5 in 2080 s by $-17.2 \%$. While for Kunshan, the values can be found under RCP8.5 in 2020s by $-9.1 \%$ and under RCP8.5 in 2080s by $-35.9 \%$, respectively. The decreasing magnitude was generally larger at the southern stations simultaneously accompanying with more humid climate than northern ones. While with $\mathrm{CO}_{2}$ fertilization, the magnitudes of decline in rice yield under all schemes would be weaken, especially in Kaifeng under RCP6.0 in 2020s as well as under RCP8.5 in 2020s and 2050s, when the rice yields would instead increase relative to that under baseline, suggesting that there were considerably positive effect of $\mathrm{CO}_{2}$ fertilization on rice yield. Although more obvious spatial variability in the responses of ET and IR to future climate change could be found as compared with the growth duration and yield, from 2020s to 2080s, all the stations present an increasing ET and IR over time with an exception of ET in 2020s in Kunshan station (Figure 8). The cumulative ET in Kaifeng would increase gradually with air warming under the four scenarios from 2020s to 2080s with the maximum value of $55.8 \%$ occurring in 2080 s under RCP8.5 without consideration of $\mathrm{CO}_{2}$ 
fertilization. As for Nanjing station, the cumulative ET would also experience a clear rise in all schemes with the maximum value of $54.3 \%$ occurring in 2080s under RCP8.5. While for Kunshan station, different with ET in other two stations, the cumulative ET in rice growing period would decrease in 2020s under four scenarios except RCP2.6, although in 2050s and 2080s, the ET would also increase under four scenarios. Compared with ET, although IR present similar changing behavior with a consistent increase for all stations in all schemes, more apparent spatial differences can be found (Figure 8). In Kaifeng station, the magnitude of IR increase would range from $8.5 \%$ under RCP6.0 in 2020s to $34.9 \%$ under RCP8.5 in 2080s. While in Nanjing stations, the magnitude of IR increase would range from $42.7 \%$ under RCP6.0 in 2020s to $123.6 \%$ under RCP8.5 in 2080s. As for the Kunshan station, the corresponding values ranges from $11.6 \%$ under RCP6.0 in 2020 s to $84.67 \%$ under RCP8.5 in 2080s. Unlike that of yield, for both the ET and IR, the differences of their changes between with/without $\mathrm{CO}_{2}$ fertilization were very small. Meanwhile, the effect of the elevated $\mathrm{CO}_{2}$ fertilization on ET and IR simulated in different schemes is not consistent.

\subsubsection{Projection of changes in WUE and IWUE with and without $\mathrm{CO}_{2}$ fertilization}

The effects of future climate change on water use efficiency (hereafter WUE) and irrigation water use efficiency (hereafter IWUE), defined respectively as the ratio of simulated yield to ET and the ratio of simulated yield to IR, representing water productivity, were also investigated. Figure 9 demonstrates the relative change of WUE and IWUE compared with that under baseline under the four RCPs scenarios with and without considering $\mathrm{CO}_{2}$ fertilization effect. For all three stations, despite the obvious differences in the changing amplitude among the different RCPs scenario and future stages, the WUE and IWUE would experience a consistent drop in all schemes on matter whether or not the $\mathrm{CO}_{2}$ fertilization effects were considered. Concurrently, the magnitude of WUE and IWUE decrease gradually enlarged from 2020s to 2080s with air warming. The WUE and 
IWUE values for rice would be reduced more than $25 \%$ and $30 \%$ under all the four RCPs in 2080 s. The maximum decline in WUE and IWUE were found in Kunshan in 2080s under RCP8.5 with the value of $-59.7 \%$ and in Nanjing in 2080s under RCP8.5 with the value of $-70.2 \%$, respectively. The remarkable decline in WUE and IWUE projected in the 21 st century resulted from decreased yield and noticeably increase ET and IR. When the $\mathrm{CO}_{2}$ fertilization effects were considered, the magnitudes of decrease in WUE and IWUE in all schemes would be mitigated, especially for the IWUE in 2050s in Nanjing under RCP2.6, when the percentage of IWUE decrease would be cut in half. With $\mathrm{CO}_{2}$ fertilization, the related maximum decline WUE and IWUE were found under the same schemes with the values of $55.5 \%$ and $67.5 \%$, respectively. In general, compared with the WUE and IWUE change without $\mathrm{CO}_{2}$ fertilization, considerably less drop in these two water productivity variables could be found with $\mathrm{CO}_{2}$ fertilization effect considering, suggesting that the enriched $\mathrm{CO}_{2}$ can improve the water use efficiencies to a larger degree.

\section{Discussion}

Agricultural production and water resource utilization are generally recognized as the most sensitive sectors to climate change in broad regions of the world and are thus affected dramatically by the ongoing climate change [Peng et al., 2004; IPCC, 2007; Piao et al., 2010]. The consequently considerable concerns on the key vulnerabilities and risks from future climate change in terms of regional food and water resources security highlight the urgent need to project the potential impacts of climate change on agricultural productivity, irrigation water requirement and utilization. The amount and extent of the researches [e.g., Tao et al., 2003; Challinor et al., 2005; Lin et al., 2005; Chavas et al., 2009; Nkomozepi and Chung, 2012; Wang et al., 2014a] documented in the introduction section on evaluating climate change effect on crop growth, water consumption and utilization efficiency driving the physical-based crop model with global climate model (GCM) or 
regional climate model ( $\mathrm{RCM})$ reflect the considerate the importance the this topic. However, estimations of climate change impact are plagued with the inevitable uncertainties from the section of the plausible future climate scenarios [Tao et al., 2008; Asseng et al., 2013; Li et al., 2015], because different GCM ensembles give different results [Meehl et al., 2007], making it hard for adaptation decision-making for food and water resources safety concerning reliable agricultural production and water utilization response. Thus, in this study, operating crop model ORYZA2000 with merged multi-model ensemble climatic data by means of the state-of-art Bayesian model averaging (BMA) approach, we construct more reliable projection in responding behaviors of rice growth and water utilization to future climate change in three typical rice plantation sites (i.e., Kaifeng, Nanjing and Kunshan) in China. For all the six climatic variables of crop model input, the multi-model ensembles projections can capture the temporal changing processes with consistent results of the observation in the past climate (Figure 5). Meanwhile, the inter-comparison among ensemble performance by BMA, SA and single GCM illustrated by the Taylor diagrams (Figure 6) shows the BMA method yield the closest climatic information to observation data with the lowest bias for all the six climatic factors relative to no matter the SA method or the individual climate model, indicating that the BMA approach for merging the four GCMs outputs is reliable and robust.

Driving the ORYZA2000 model with the merging future climatic data, some important index of crop growth and water consumption were projected in the 21 st century. For most schemes (combination of different emission scenarios and future periods), the average rice growth duration for all three stations would be shortened under the obvious climate warming condition (Table 4). Nevertheless, the average rice growth duration under RCP8.5 in 2080s would be remarkably lengthened, especially for the two stations (i.e., Nanjing and Kunshan) in the Yangtze River Basin. This point appears to be inconsistent with the previous studies in this region [e.g., Shen et al., 2011]. 
As a matter of fact, along with the increase of air temperature, the crop growth duration would not be shorten continuously. This is particularly true for the rice in southern China. A single-peaked curve of the relationship between the length of growth period and air temperature with an optimum temperatures at about $25.7^{\circ} \mathrm{C}$ was found based on 29 experimental sites across South China [ $\mathrm{Lu}$ et al., 2008]. In an earlier study by Zhao et al. [2007], the maximum temperature was proved to play a critical role in the rice development, especially at the flowering stage, when percentage of undeveloped of gain increases as mean maximum temperature rises. Evidence still exists in other regions that biomass is highly sensitive to heat because of increased occurred of spikelet sterility [e.g., Kim et al., 1996; Prasad et al., 2006].

For the three stations, the sharp increases in maximum temperature were projected under RCP8.5 in 2080s ranging from 6.0 to $9.0^{\circ} \mathrm{C}$ (Table 4). This partly explained why the growth period become longer instead in this period. This inference can be further confirmed by the decline in rice yield projected in all future stages without exception (Figure 8) in despite of some spatial variability, especially in 2080s. This generally negative effect of global warming on rice yield has been reach a consensus by many researchers [e.g., Peng et al., 2004; Tao et al., 2008; Li et al., 2015] no matter through observation or modeling, although the sensitivity of yield to temperature were reported to be discrepancy between low and high latitude [Rosenzweig et al., 2014].

Meanwhile, although the $\mathrm{CO}_{2}$ fertilization effects can not completely compensate for the assimilation reduction due to the air temperature rising, which was represented by that the rice yield in all schemes with $\mathrm{CO}_{2}$ fertilization would still be reduced in all stations, the results of comparison of simulated rice yields with and without $\mathrm{CO}_{2}$ fertilization indicate that the increase of $\mathrm{CO}_{2}$ fertilization under future climate is conductive to raise the rice yield. This finding was confirmed by many similar simulation researches [e.g., Shen et al., 2011; Li et al., 2015] and hold for other 
crops in special chamber experiment [e.g., Reddy et al., 1995; Kim et al., 2007; Hamilton et al., 2008; Bannayan et al., 2009]. Nevertheless, the interactive impact of $\mathrm{CO}_{2}$ and temperature on fieldgrown rice is still complicated and remains uncertain due to the photosynthetic acclimation to the elevated $\mathrm{CO}_{2}$ [Konzmann et al., 2013; Adachi et al., 2014].

The general increasing behaviors in ET were projected with air warming at all stations during the 21 st century. This result has also been confirmed by the other global studies with employing the simple water balance model based on CMIP5 [e.g., Wada et al., 2013]. Meanwhile, a gradual increasing pattern for ET change can be roughly revealed both over space and time from 2020s to 2080s and from south to north. More notably, the increasing trend can be found in future IR due to the decline of precipitation in crop growing period (Figure 10), especially for the two stations (i.e., Nanjing and Kunshan) in the Yangtze River Basin with the maximum value by $123.6 \%$ in 2080s under RCP8.5. It should be specially noted that the widespread annual precipitation increase in China was generally pronounced in the recent national scale future climate projection researches [e.g., Wang and Chen, 2014; Yin et al., 2015]. Our simulation results of the merging GCM precipitation output in the study area based on BMA in fact confirmed this phenomenon. However, the precipitation pattern in crop growing season presented adverse direction compared with that in annual scale (see Figure 10), especially for Nanjing and Kunshan stations, leading to a more remarkable increasing irrigation water requirement in this region together with the increase in ET. Furthermore, unlike the effect on yield, our simulation results showed that the effect of the elevated $\mathrm{CO}_{2}$ fertilization on ET and IR were inconsistent for the three stations. Accompanying with the significant reduction in rice production and enlargement in ET and IR, the WUE and IWUE showed consistently decreasing trends in the three stations for almost all schemes. However, these situations would be alleviated with consideration of the $\mathrm{CO}_{2}$ fertilization effects, which were 
reported by the similar studies [e.g., Mo et al., 2009; Guo et al., 2010]. Given these analysis above, multiple-fold adaptation countermeasures in cultivars and irrigation should be bred to avoid the adverse impact of future climate change, but to take the advantages of the positive effect of $\mathrm{CO}_{2}$ fertilization to ensure the sustainable development of agricultural production and water resources management.

With the multi-climate projections merged by BMA method driving the crop model, the uncertainties of the future picture of how rice production, water consumption and water utilization response to the future climate change alone were alleviated in this study. However, other inevitable uncertainties associated with the projected rice yield, ET, IR, WUE and IWUE in this study still limit the universality of the conclusion. For example, crop models differ in the way they simulate dynamic processes, set parameters and use input variables, causing large differences in simulation results [Palosuo et al., 2011], which was revealed to account for a greater proportion of the uncertainty than that due to the variations among the downscaled GCMs [Asseng et al., 2013]. While most climate change impact assessments on agriculture and water resources, including the current study, have only employed one crop model, always limiting the quantification of uncertainty [Müller, 2011]. Recently, the AgMIP rice team, with employing 13 models, estimated the uncertainties in yield and biomass projection and further tested the hypothesis that an ensemble of models reduces uncertainties [Li et al., 2015]. They found that the uncertainty of rice yield predictions with an ensemble of eight models calibrating for phenology or five models calibrating in detail against well-controlled field experiments can be reduced to the typical deviation level of measured yield in agronomic field [Belder et al., 2007]. Although there are inherent differences in the growing environments between rice and other crops, the similar number of models required for robust estimation was presented by the AgMIP Wheat team [Asseng et al., 2013] and Maize team 
[Bassu et al., 2014]. In addition, our simulated results take into account only the effects of climate factors on rice growth and water utilization under scenarios of full irrigation and adequate access to nutrients, and consequently should be interpreted cautiously. In practice, farmers may experience effects of rice varieties changes, biotic stress such as pests, diseases and weed infestations, irrigated and fertilized conditions management, which all impact crop growth and water consumption formation. Generally, an effort is underway to conduct the compressive exploration under the support of multiple process-based models with consideration of interaction of possible anthropogenic suboptimal management, biological behavior and environmental factors.

\section{Conclusion}

In this study, with introducing a Bayesian model averaging (BMA) method, based on 4 GCMs under four pathways from the CMIP5, the responses of rice yield, water consumption and irrigation requirement as well as water use efficiency to future climate scenarios of 21 st century using multimodel ensemble projection in three typical rice plantation sites (i.e., Kaifeng, Nanjing and Kunshan) of China were comprehensibly projected by driving a well-validated ORYZA2000 rice model with multi-model ensembles projected climatic output. The multi-model ensembles projection can capture the changing behaviors of climatic factors better with more consistent results of the historical observation in comparison with the simple averaging method and individual model, indicating that projection based on the BMA ensemble method is competent to produce ensembles with the lowest bias. The average rice growth duration would be generally shortened for all the three stations under four scenarios, except that under RCP8.5 scenario in 2080s period, when the rice development would decelerate due to the sharp increase in maximum temperature. In despite of the distinct response of the growth duration to future climate change for the three stations, the rice yield would be reduced significantly under the climate warming condition. IR would present 
more remarkable increase compared with the ET, especially for Nanjing and Kunshan stations, due to the decrease in precipitation during the rice growth period. Accompanying with the significant reduction in rice production and enlargement in ET and IR, the WUE and IWUE showed consistently decreasing trends in the three stations for almost all schemes. Furthermore, although the $\mathrm{CO}_{2}$ fertilization effect cannot compensate the negative effect of temperature increase, comparisons of simulation results with and without $\mathrm{CO}_{2}$ fertilization indicated that the increase of $\mathrm{CO}_{2}$ concentration can promote the overall level of yield and thus improve the water use efficiencies of rice in the study area.

\section{Acknowledgments}

This work was financially supported by the National Science Foundation of China (51379057), the Fundamental Research Funds for the Central Universities (2015B14114), National 'Ten Thousand Program' Youth Talent Support Program and the QingLan Project. Thanks to the National Meteorological Information Center, China Meteorological Administration (http://data.cma.gov.cn/) for offering the meteorological data and also thanks to the Working Group of the World Climate Research Program on Coupled Modeling, which is responsible for CMIP5. In addition, the authors gratefully acknowledge the IRRI for sharing the validated ORYZA model for Kaifeng and Nanjing on the Internet. Cordial thanks are also extended to the Associate Editor, Professor Anne Verhoef, and anonymous referee for their valuable comments. 


\section{References}

Adachi, M., T. Hasegawa, H. Fukayama, T. Tokida, H. Sakai, T. Matsunami, H. Nakamura, R. Sameshima, and M. Okada (2014), Soil and water warming accelerates phenology and downregulation of leaf photosynthesis of rice plants grown under free-air $\mathrm{CO}_{2}$ enrichment (FACE), Plant Cell Physiol., 55, 370-380.

Aggarwal, P. K., and R. K. Mall, (2002), Climate change and rice yields in diverse agroenvironments of India. II. Effect of uncertainties in scenarios and crop models on impact assessment, Clim. Change, 52(3), 331-343.

Alan, D., Z. Justin, S. P. M. Edwin, N. Bart, F. W. Eric, and P. L. Dennis (2003), Detection of intensification in global and continental-scale hydrological cycles: temporal scale of evaluation, J. Clim., 16, 535-547.

Asseng, S., F. Ewert, C. Rosenzweig et al. (2013), Uncertainty in simulating wheat yields under climate change, Nat. Clim. Change, 3(9), 827-832.

Arora, V. K. (2006), Application of a rice growth and water balance model in an irrigated semi-arid subtropical environment, Agric. Water Manage., 83, 51-57.

Bannayan, M., C. M. T. Soler, A. Garcia, Y. Garcia, L. C. Guerra, and G. Hoogenboom (2009), Interactive effects of elevated $\mathrm{CO}_{2}$ and temperature on growth and development of a short- and long-season peanut cultivar, Clim. Change, 93, 389-406.

Bassu, S., N. Brisson, J. L. Durand et al. (2014), How do various maize crop models vary in their responses to climate change factors? Global Change Biol., 20, 2301-2320.

Bates, B. C., Z. W. Kundzewicz, S. Wu and J. P. Palutikof, (eds) (2008), Climate change and water, Tech. Paper Intergovern. Panel on Clim. Change, Geneva: IPCC Secretariat.

Belder, P., B. A. M. Bouman, and J. H. J. Spiertz (2007), Exploring options for water saving in 
lowland rice using a modeling approach, Agric. Syst., 92, 91-114.

Boling, A., B. A. M. Bouman, T. P. Tuong, M. V. R. Murty, and S. Y. Jatmiko (2007), Modeling the effect of groundwater depth on yield-increasing interventions in rainfed lowland rice in Central Java, Indonesia, Agric. Syst., 92, 115-139.

Bouman, B. A. M., H. van Keulen, H. H. van Laar, and R. Rabbinge (1996), The 'School of de Wit' crop growth simulation models: pedigree and historical overview, Agric. Syst., 52, 171-198.

Bouman, B. A. M., M. J. Kropff, T. P. Tuong, M. C. S. Wopereis, H. F. M. ten Berge, and H. H. van Laar (2001), ORYZA2000: modeling lowland rice, International Rice Research Institute, Wageningen University and Research Centre, Los Baños, Philippines Wageningen, The Netherlands.

Bouman, B. A. M., and H. H. van Laar (2006), Description and evaluation of the rice growth model ORYZA2000 under nitrogen-limited conditions, Agric. Syst., 87, 249-273.

Bouman, B. A. M., R. M. Lampayan, and T. P. Tuong (2007), Water Management in Irrigated Rice: Coping with Water Scarcity, International Rice Research Institute, Los Baños, Philippines Wageningen, The Netherlands.

Brumbelow, K., and A. Georgakakos (2001), An assessment of irrigation needs and crop yield for the United States under potential climate changes, J. Geophys. Res., 106, 27383-27405.

Cabangon, R., G. Lu, T. P. Tuong, B. A. M. Bouman, Y. Feng, and Z. Zhang (2003), Irrigation management effects on yield and water productivity of inbred and aerobic rice varieties in Kaefeng, Proceedings of the First International Yellow River Forum on River Basin Management, vol. 2, The Yellow River Conservancy Publishing House, Zhengzhou, Henan, China.

Challinor, A. J., T. R. Wheeler, P. Q. Craufurd, and J. M. Slingo (2005), Simulation of the impact 
of high temperature stress on annual crop yields, Agric. For. Meteorol., 135, 180-189.

Challinor, A. J., and T. R. Wheeler (2008), Crop yield reduction in the tropics under climate change: processes and uncertainties, Agric. For. Meteorol., 148, 343-356.

Chavas, D. R., R. C. Izaurralde, A. M. Thomson, and X. Gao (2009), Long-term climate change impacts on agricultural productivity in eastern China, Agric. For. Meteorol., 149, 1118-1128.

Cong, Z., S. Wang, and G. Ni (2008), Simulations of the impact of climate change on winter wheat production, J. Tsinghua Univ. (Sci. Tech.) 48(9), 46-50.

De Silva, C. S., E. K. Weatherhead, J. W. Knox, and J. A. Rodriguez-Diaz (2007), Predicting the impacts of climate change: A case study of paddy irrigation water requirements in Sri Lanka, Agric. Water Manage., 93, 19-29.

Dempster, A. P., N. M. Laird, and D. B. Rubin (1977), Maximum likelihood from incomplete data via the EM algorithm, J. Roy. Stat. Soc. Ser., A, 39B, 1-39.

Döll, P. (2002), Impact of climate change and variability on irrigation requirement: a global perspective, Clim. Change, 54, 269-293.

Duan, Q., N. K. Ajami, X. Gao, and S. Sorooshian (2007), Multi-model ensemble hydrologic prediction using Bayesian model averaging, Adv. Water Resour., 30(5), 1371-1386.

Duan, Q., and T. J. Phillips (2010), Bayesian estimation of local signal and noise in multimodel simulations of climate change, J. Geophys. Res., 115, D18123.

Easterling, W. E., P. K. Aggarwal, P. Batima et al. (2007), Food, fibre and forest products, In: Climate Change 2007: Impacts, Adaptation and Vulnerability, Contribution of Working Group II to the Fourth Assessment Report of the Intergovernmental Panel on Climate Change, Cambridge Univ. Press, Cambridge, UK.

FAO (2010), Food and Agriculture Organization of the United Nations, http://faostat3.fao.org (last 
visited: 22.9.2015).

Feng, L., B. A. M. Bouman, T. P. Tuong, R. J. Cabangon, Y. Li, G. Lu, and Y. Feng (2007), Exploring options to grow rice using less water in northern China using a modelling approach I. Field experiments and model evaluation, Agric. Water Manage., 88, 1-13.

Fischer, G., F. N. Tubiello, H. V. Velthuizen, and D. A.Wiberg (2007), Climate change impacts on irrigation water requirement: effects of mitigation, 1990-2080, Technol. Forecast Soc. Change, $74,1083-1107$.

Godfray, H. C. J., J. R. Beddington, I. R. Crute, L. Haddad, D. Lawrence, J. F. Muir, J. Pretty, S. Robinson, S. M, Thomas, and C. Toulmin (2010), Food security: The challenge of feeding 9 billion people, Science, 327, 812-818.

Guo, R., Z. Lin, X. Mo, and C. Yang (2010), Responses of crop yield and water use efficiency to climate change in the North China Plain, Agric. Water Manage., 97, 1185-1194.

Guo, S., J. Guo, Y. Hou, L. Xiong, and X. Hong (2015), Prediction of future runoff change based on Budyko hypothesis in Yangtze River basin, Adv. Water Sci., 26, 151-160. (In Chinese with English abstract)

Hamilton III, E. W., S. A. Heckathorn, P. Joshi, D. Wang, and D. Barua (2008), Interactive effects of elevated $\mathrm{CO}_{2}$ and growth temperature on the tolerance of photosynthesis to acute heat stress in C3 and C4 species, J. Integr. Plant Biol., 50 (11), 1375-1387.

Hoeting, J. A., D. Madigan, A. E. Raftery, and C. T. Volinsky (1999), Bayesian model averaging: A tutorial, Stat. Sci., 14(4), 382-417.

Houghton, J. T. A. Y. Ding, D. J. Griggs, M. Noguer, P. J. van der Linden, X. Dai, K. Maskell, and C. A. Johnson, (eds) (2001), Climate Change 2001: The Scientific Basis, Contribution of Working Group I to the Third Assessment Report of the Intergovernmental Panel on Climate 
Change, pp. 892, Cambridge Univ. Press, New York.

Huntiugton, T. G. (2006), Evidence for intensification of the global water cycle: review and synthesis, J. Hydrol., 319, 83-95.

IPCC (2007), Summary for policymakers, In Climate Change 2007: The Physical Science Basis, Contribution of Working Group I to the Fourth Assessment Report of the Intergovernmental Panel on Climate Change, Cambridge Univ. Press, Cambridge, U.K. and New York.

IPCC (2013), Summary for Policymakers, In Working Group I Contribution to the IPCC Fifth Assessment Report Climate Change 2013: The Physical Science Basis. Cambridge Univ. Press, Cambridge, UK.

Karim, M. R., M. Ishikawa, M. Ikeda, and M. T. Islam (2012), Climate change model predicts 33\% rice yield decrease in 2100 in Bangladesh, Agron. Sustain. Dev., 32, 821-830.

Kim, H. Y., T. Horie, H. Nakagawa, and K. Wada (1996), Effects of elevated $\mathrm{CO}_{2}$ concentration and high temperature on growth and yield of rice: 1 . The effect on development, dry matter production and some growth characteristics, Jpn. J. Crop Sci., 65, 634-643.

Kim, S., D. C. Gitz, R. C. Sicher, J. T. Baker, D. J. Timlin, and V. R. Reddy (2007), Temperature dependence of growth, development, and photosynthesis in maize under elevated $\mathrm{CO}_{2}$, Environ. Exp. Bot., 61, 224-236.

Konzmann, M., D. Gerten, and J. Heinke (2013), Climate impacts on global irrigation requirements under 19 GCMs, simulated with a vegetation and hydrology model, Hydrol. Sci. J., 58, 88-105.

Krishnamurti, T. N., C. M. Kishtawal, T. LaRow, D. Bachiochi, Z. Zhang, C. E. Williford, S. Gadgil, and S. Surendran (1999), Improved weather and seasonal climate forecasts from multimodel super ensembles, Science, 285, 1548-1550.

Li, H., J. Sheffield, and E. F. Wood (2010), Bias correction of monthly precipitation and 
temperature fields from Intergovernmental Panel on Climate Change AR4 models using equidistant quantile matching, J. Geophys. Res., 115, D10101.

Li, T., T. Hasegawa, X. Yin et al. (2015), Uncertainties in predicting rice yield by current crop models under a wide range of climatic conditions, Global Change Biol., 21, 1328-1341.

Lin, E., W. Xiong, H. Ju, Y. Xu, Y. Li, L. Bai, and L. Xie (2005), Climate change impacts on crop yield and quality with $\mathrm{CO}_{2}$ fertilization in China, Philos. Trans. R. Soc., B360, 2149-2154.

Liu, B., M. Xu, M. Henderson, and W. Gong (2004), A spatial analysis of pan evaporation trends in China, 1955-2000, J. Geophys. Res. Atmos., 109(D15), D15102.

Liu, S., X. Mo, Z. Lin, Y. Xu, J. Ji, G. Wen, and J. Richey (2010), Crop yield responses to climate change in the Huang-Huai-Hai Plain of China, Agric. Water Manage., 97, 1195-1209.

Lobell, D. B., M. Banziger, C. Magorokosho, and B. Vivek (2011), Nonlinear heat effects on African maize as evidenced by historical yield trials, Nat. clim. change, 1, 42-45.

Lu, P., Q. Yu, E. Wang, J. Liu, and S. Xu (2008), Effects of climatic variation and warming on rice development across South China, Clim. Res., 36, 79-88.

Luo, Y., Y. Jiang, S. Peng, Y. Cui, S. Khan, Y. Li, and W. Wang (2015), Hindcasting the effects of climate change on rice yields, irrigation requirements, and water productivity, Paddy Water Environ., 13, 81-89.

Madigan, D., A. E. Raftery, C. T. Volinsky, and J. A. Hoeting (1999), Bayesian model averaging, Stat. Sci., 14, 382-401.

McLachlan, G. J., and T. Krishnan (1997), The EM Algorithm and Extensions, Wiley, pp. 274.

Meehl, G. A., C. Covey, and K. E. Taylor (2007), The WCRP CMIP3 multimodel Dataset: a new era in climate change research, B. Am. Meteorol. Soc., 88, 1383-1394.

Min, S. K., A. Hense, H. Paeth, and W. T. Kwon (2004), A Bayesian decision method for climate 
change signal analysis, Meteorol. Z., 13, 421- 436.

Min, S. K., A. Hense, and W. T. Kwon (2005), Regional-scale climate change detection using a Bayesian decision method, Geophys. Res. Lett., 32, L03706.

Min, S. K., and A. Hense (2006), A Bayesian approach to climate model evaluation and multimodel averaging with an application to global mean surface temperatures from IPCC AR4 coupled climate models, Geophys. Res. Lett., 33, L08708.

Mo, X., S. Liu, Z. Lin, and R. Guo (2009), Regional crop yield, water consumption and water use efficiency and their responses to climate change in the North China Plain, Agric. Ecosyst. Environ., 134, 67-78.

Müller, C. (2011), Agriculture: Harvesting from uncertainties, Nat. Clim. Change, 1, 253-254.

National Bureau of Statistics of China (2009), China Statistical Yearbook 2009, http://www.stats.gov.cn/tjsj/ndsj/2009/indexeh.htm (last visited: 22.9.2015).

Nkomozepi, T., and S. O. Chung (2012), Assessing the trends and uncertainty of maize net irrigation water requirement estimated from climate change projections for Zimbabwe, Agric. Water Manage., 111, 60-67.

Palosuo, T., K. C. Kersebaum, C. Angulo, P. Hlavinka, M. Moriondo, J. E. Olesen, R. H. Patil, F. Ruget, C. Rumbaur, J. Takac, M. Trnka, M. Bindi, B. Caldag, F. Ewert, R. Ferrise, W. Mirschel, L. Saylan, B. Siska, and R. Rotter (2011), Simulation of winter wheat yield and its variability in different climates of Europe: A comparison of eight crop growth models, Eur. J. Agron., 35(3), 103-114.

Parry, M. L., C. Rosenzweig, A. Iglesias, M. Livermore, and C. Fischer (2004), Effects of climate change on global food production under SRES emissions and socioeconomic scenarios, Global Environ. Change, 14, 53-67. 
Peng, S. B., K. T. Ingram, H. U. Neue, and L. H. Ziska (1995), Climate Change and Rice, International Rice Research Institute, Springer-Verlag, Berlin, Heidelberg, Germany.

Peng, S. B., J. L. Huang, and E. S. John (2004), Rice yields decline with higher night temperature from global warming, PNAS, 101 (27), 9971-9975.

Piao, S., P. Ciais, Y. Huang, Z. Shen, S. Peng, J. Li, L. Zhou, H. Liu, Y. Ma, Y. Ding, P. Friedlingstein, C. Liu, K. Tan, Y. Yu, T. Zhang, and J. Fang (2010), The impacts of climate change on water resources and agriculture in China, Nature, 467, 43-51.

Prasad, P. V. V., K. J. Boote, L. H. Allen, J. E. Sheehy, and J. M. G. Thomas (2006), Species, ecotype and cultivar differences in spikelet fertility and harvest index of rice in response to high temperature stress, Field Crops Res., 95, 398-411.

Raftery, A. E., D. Madigan, and J. A. Hoeting (1997), Bayesian model averaging for linear regression models, J. Am. Stat. Assoc., 92, 179-191.

Raftery, A. E., T. Gneiting, F. Balabdaoui, and M. Polakowski (2005), Using Bayesian model averaging to calibrate forecast ensembles, Mon. Weather Rev., 133, 1155-1174.

Reddy, V. R., K. R. Reddy, and B. Acock (1995), Carbon dioxide and temperature interactions on stem extension, node initiation, and fruiting in cotton, Agric. Ecosys. Environ., 55 (1), 17-28.

Rosenzweig, C., J. Elliott, D. Deryng et al. (2014), Assessing agricultural risks of climate change in the 21 st century in a global gridded crop model intercomparison, PNAS, 111, 3268-3273.

Shen, S., S. Yang, Y. Zhao, Y. Xu, X. Zhao, Z. Wang, J. Liu, and W. Zhang (2011), Simulating the rice yield change in the middle and lower reaches of the Yangtze River under SRES B2 scenario, Acta. Ecol. Sin., 31, 40-48.

State Environmental Protection Administration (2003), Progress Report of Trade Liberalization in the Agriculture Sector and the Environment, with Specific Focus on the Rice Sector in China, 
State Environmental Protection Administration, Available at http://www.unep.ch/etb/events/Events2003/pdf/FinalDraftofChinaStudy.pdf (last visited: 22.9.2015).

Taylor, K. (2001), Summarizing multiple aspects of model performance in a single diagram, $J$. Geophys. Res., 106(D7), 7183-7192.

Taylor, K. E., R. J. Stouffer, and G. A. Meehl (2012), An overview of CMIP5 and the experiment design, Bull. Am. Meteorol. Soc., 93, 485-498.

Tao, F., M. Yokozawa, Y. Hayashi, and E. Lin (2003), Future climate change, the agricultural water cycle, and agricultural production in China, Agric. Ecosyst. Environ., 95, 203-215.

Tao, F., Y. Hayashi, Z. Zhang, T. Sakamoto, and M. Yokozawa (2008), Global warming, rice production, and water use in China: developing a probabilistic assessment, Agric. For. Meteorol., $148,94-110$.

Tao, F., Z. Zhao, and Y. Masayuki (2011), Dangerous levels of climate change for agricultural production in China, Reg. Environ. Change, 11(Suppl 1), S41-S48.

Tao, F., Z. Zhang, W. Shi, Y. Liu, D. Xiao, S. Zhang, Z. Zhu, M. Wang, and F. Liu (2013), Single rice growth period was prolonged by cultivars shifts, but yield was damaged by climate change during 1981-2009 in China, and late rice was just opposite, Glob. Change Biol., 19(10), 32003209.

Thomoson, A. M., R. C. Izaurralde, N. J. Rosenberg, and X. He (2006), Climate change impacts on agriculture and soil carbon sequestration potential in the Huang-Hai Plain of China, Agric. Ecosyst. Wnviron., 114, 229-249.

van Ittersum, M. K., P. A. Leffelaar, H. van Keulen, M. J. Kropff, L. Bastiaans, and J. Goudriaan (2003), On approaches and applications of the Wageningen crop models, Eur. J. Agron., 18, 
Vislocky, R. L., and J. M. Fritsch (1995), Improved model output statistics forecasts through model consensus, B. Am. Meteorol. Soc., 76, 1157-1164.

Wada, Y., D. Wisser, S. Eisner, M. Florke, D. Gerten, I. Haddeland, N. Hanasaki, Y. Masaki, F. T. Portmann, T. Stacke, Z. Tessler, and J. Schewe (2013), Multimodel projections and uncertainties of irrigation water demand under climate change, Geophys. Res. Lett., 40, 4626-4632.

Wang. L., and W. Chen (2013), Equiratio cumulative distribution function matching as an improvement to the equidistant approach in bias correction of precipitation, Atmos. Sci. Let., 15, $1-6$.

Wang, L., and W. Chen (2014), A CMIP5 multimodel projection of future temperature, precipitation, and climatological drought in China, Int. J. Climatol., 34, 2059-2078.

Wang, W., Q. Shao, T. Yang, S. Peng, Z. Yu, J. Taylor, W. Xing, C. Zhao, and F. Sun (2013), Changes in daily temperature and precipitation extremes in the Yellow River Basin, China. Stochastic Environ. Res. Risk Assess., 27, 401-421.

Wang, W., Z. Yu, Z. Zhang, Q. Shao, Y. Zhang, Y. Luo, X. Jiao, and J. Xu (2014a), Responses of rice yield, irrigation water requirement and water use efficiency to climate change in China: Historical simulation and future projections, Agric. Water Manage., 146, 249-261.

Wang, W., Q. Shao, T. Yang, Z. Yu, W. Xing, and C. Zhao (2014b), Multimodel ensemble projections of future climate extreme changes in the Haihe River Basin, China, Theor. Appl. Climatol., 118, 405-417.

Wilson, L. J., S. Beauregard, A. E. Raftery, and R. Verret (2007), Calibrated surface temperature forecasts from the Canadian ensemble prediction system using Bayesian model averaging, Mon. Weather Rev., 135, 1364-1385. 
Wu, H., X. Zhang, S. Liang, H. Yang, and G. Zhou (2012), Estimation of clear-sky land surface longwave radiation from MODIS data products by merging multiple models, J. Geophys. Res., 117, D22107.

Xing, W., W. Wang, Q. Shao, S. Peng, Z. Yu, B. Yong, and J. Taylor (2014), Changes of reference evapotranspiration in the Haihe River Basin: Present observations and future projection form climatic variables through multi-model ensemble, Glob. Planet. Change, 115, 1-15.

Xiong, W., R. Matthews, I. Holman, E. Lin, and Y. Xu (2007), Modelling China's potential maize production at regional scale under climate change, Clim. Change, 85, 433-451.

Xiong, W., I. Holman, D. Conway, E. Lin, and Y. Li (2008), A crop model cross calibration for use in regional climate impacts studies, Ecol. Modell., 213, 365-380.

Xiong, W., D. Conway, E. Lin, Y. Xu, H. Ju, J. Jiang, I. Holman, and Y. Li (2009), Future cereal production in China: The interaction of climate change, water availability and socio-economic scenarios, Global Environ. Change, 19 (1), 34-44.

Xu, J., S. Peng, S. Yang, and W. Wang (2012), Ammonia volatilization loss from a rice paddy with different irrigation and nitrogen managements, Agric. Water Manage., 104, 184-192.

Yang, T., X. Wang, C. Zhao, X. Chen, Z. Yu, Q. Shao, C. Xu, J. Xia, and W. Wang (2011), Changes of climate extremes in a typical arid zone: observation and multimodel ensemble projections, $J$. Geophys. Res., 116, D19106.

Yang, T., X. Hao, Q. Shao, C. Xu, C. Zhao, X. Chen, and W. Wang (2012), Multi-model ensemble projections in temperature and precipitation extremes of the Tibetan Plateau in the 21 st century, Glob. Planet. Change, 80-81, 1-13.

Yang, X., S. Asseng, M.T.F. Wong, Q.Yu, J.Li, and E.Liu (2013), Quantifying the interactive impacts of global dimming and warming on wheat yield and water use in China, Agric. For. 
Meteorol., 182-183, 342-351.

Yao, F., Y. Xu, E. Lin, M. Yokozawa, and J. Zhang (2007), Assessing the impacts of rice yields in the main rice areas of China, Clim. Change, 80, 395-409.

Yao, Y., S. Liang, S. Zhao, Y. Zhang, Q. Qin, J. Cheng, K. Jia, X. Xie, N. Zhang, and M. Liu (2014), Validation and application of the modified satellite-based Priestley-Taylor algorithm for mapping terrestrial evapotranspiration, Remote Sens., 6, 880-904.

Yadav, S., T. Li, E. Humphreys, G. Gill, and S. S. Kukal (2011), Evaluation and application of ORYZA2000 for irrigation scheduling of puddled transplanted rice in northwest, India. Field Crops Res., 122, 104-117.

Yin, Y., Q. Tang, and X. Liu (2015), A multi-model analysis of change in potential yield of major crops in China under climate change, Earth Syst. Dynam., 6, 45-59.

Zhang, T., J. Zhu, X. Yang, and X. Zhang (2008), Correlation changes between rice yields in north and northwest China and ENSO from 1960 to 2004, Agric. For. Meteorol., 148, 1021-1033.

Zhao, H., F. Yao, Y. Zhang, B. Xu, J. Yuan, Y. Hu, and Y. Xu (2007), Correlation Analysis of Rice Seed Setting Rate and Weight of 1000-Grain and Agro-Meteorology over the Middle and Lower Reaches of the Yangtze River, China, Agric. Sci. Chin., 6(4), 430-436. 


\section{Table Captions}

Table 1 Summary of 4 general circulation models used in this study

Table 2 Calibrated parameter values of ORYZA2000 model

Table 3 Evaluation results for ORYZA2000 model over the entire growing season for the calibration and validation data sets

Table 4 Changes of precipitation $(P)$, max temperature $\left(T_{\max }\right)$, min temperature $\left(T_{\min }\right)$, radiation $(R)$, wind speed $(W)$, and vapor pressure $(E)$ in the future scenarios relative to the baseline 


\section{Figure Captions}

Figure 1 The locations of the three experimental stations

Figure 2 The simulated (solid line) and measured dry biomass over time in calibration period (A) and validation period (B) in Kunshan. Total crop (cross), Stems (rhombus), Leaves (triangle) and Panicles (square) means the dry biomass of the whole crop, stems, leaves and panicles, respectively. The inset shows the simulated vs. measured dry biomass of the whole crop. The solid line is the $1: 1$ relationship

Figure 3 Simulated (solid line) and measured leaf area index (circle) over time in calibration period (A) and validation period (B) in Kunshan

Figure 4 Weights of four GCMs for the six climate variables according to the BMA method in Kaifeng (A), Nanjing (B) and Kunshan (C)

Figure 5 The BMA simulation results of six climatic variables for basin average during 2001-2005

Figure 6 Taylor diagrams for projected (A) max temperature, (B) min temperature precipitation, (C) radiation, (D) precipitation, (E) vapor pressure, and (F) wind speed in Kunshan station evaluated against observed ones for 2001-2005. The Taylor diagrams compare actual observations with simulations by individual GCM model, the SA method as well as the BMA method, and summarize three metrics of the correlation (curved axis), the ratio of the standard deviations (x and y axes), and the RMSE (dashed line). The closer a point is to the observed data, the better the fit between observed and simulated data

Figure 7 Changes of rice growth duration under future climate scenarios relative to the baseline in Kaifeng (A), Nanjing (B) and Kunshan (C)

Figure 8 Changes of rice yield, ET and IR under future climate scenarios relative to the baseline in Kaifeng (A), Nanjing (B) and Kunshan (C) for 2020s (solid blue), 2050s (solid red) and 2080s 
(solid green). The related value was demonstrated with dashed line when $\mathrm{CO}_{2}$ fertilization effect was taken into consideration

Figure 9 Same as in Figure 8, but for WUE and IWUE

Figure 10 Monthly average precipitation of three experiment stations (Kaifeng (A), Nanjing (B) and Kunshan (C)) in 2080s under four scenarios. Histogram represent monthly mean precipitation of 4 scenarios, while gray territory represent historical monthly mean precipitation. The insert shows five years moving averaging of precipitation in 21 st century under 4 scenarios 


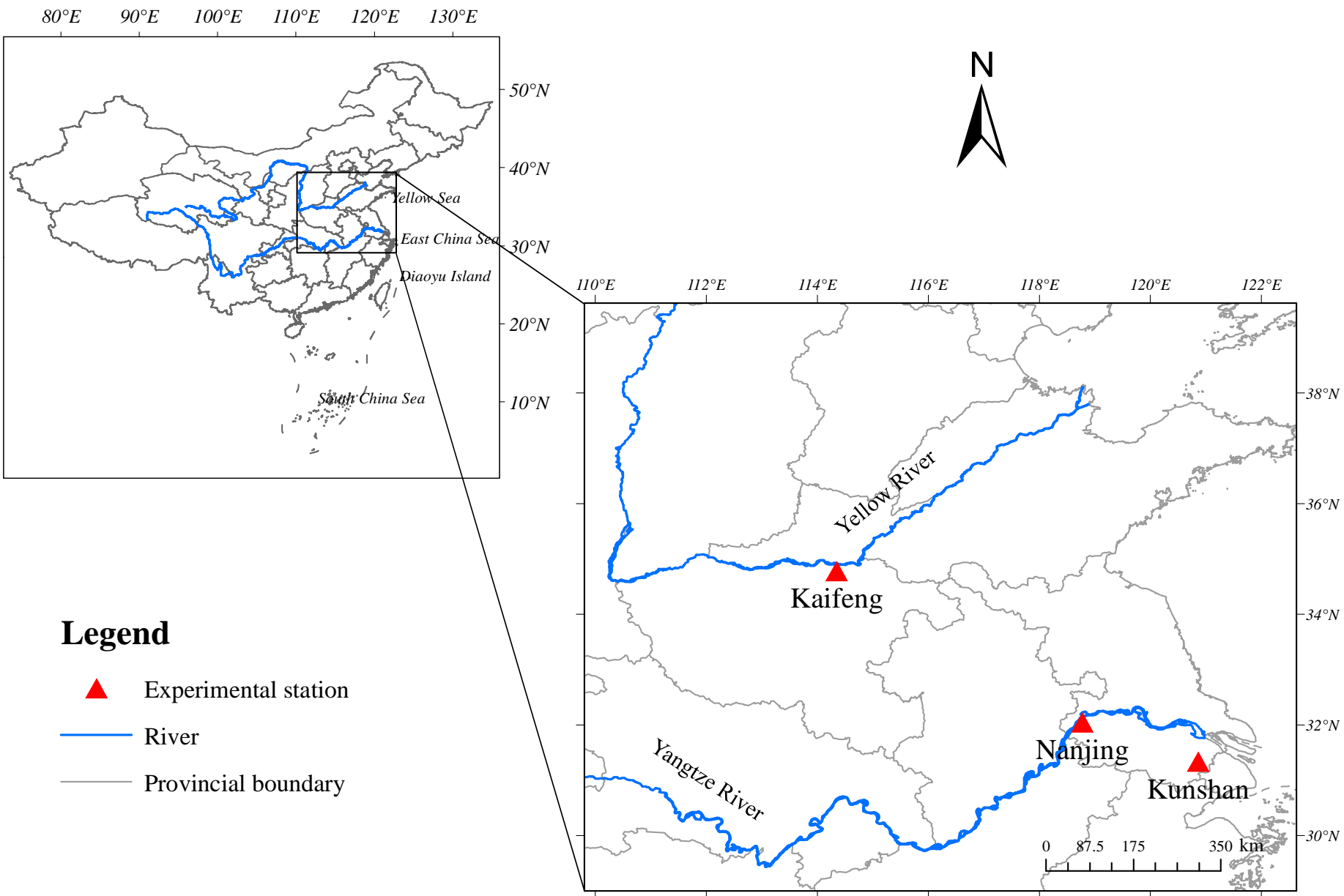

Figure 1 The locations of the three experimental stations 

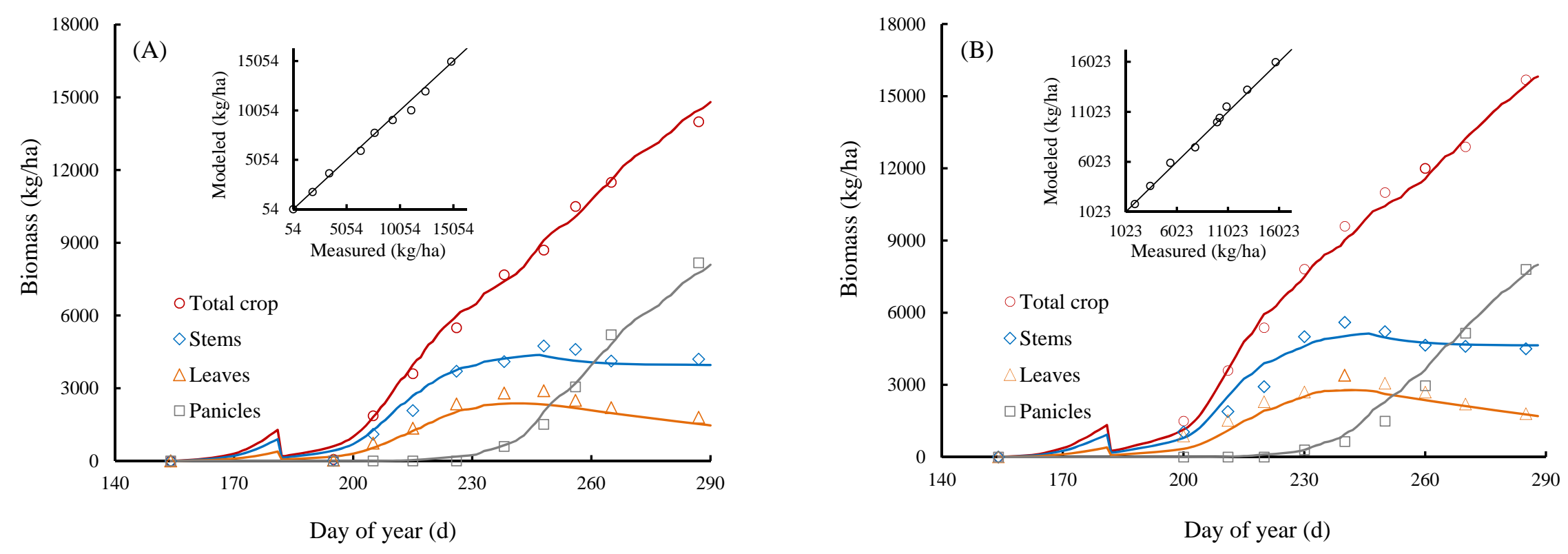

Figure 2 The simulated (solid line) and measured dry biomass over time in calibration period (A) and validation period (B) in Kunshan. Total crop (cross), Stems (rhombus), Leaves (triangle) and Panicles (square) means the dry biomass of the whole crop, stems, leaves and panicles, respectively. The inset shows the simulated vs. measured dry biomass of the whole crop. The solid line is the 1:1 relationship 

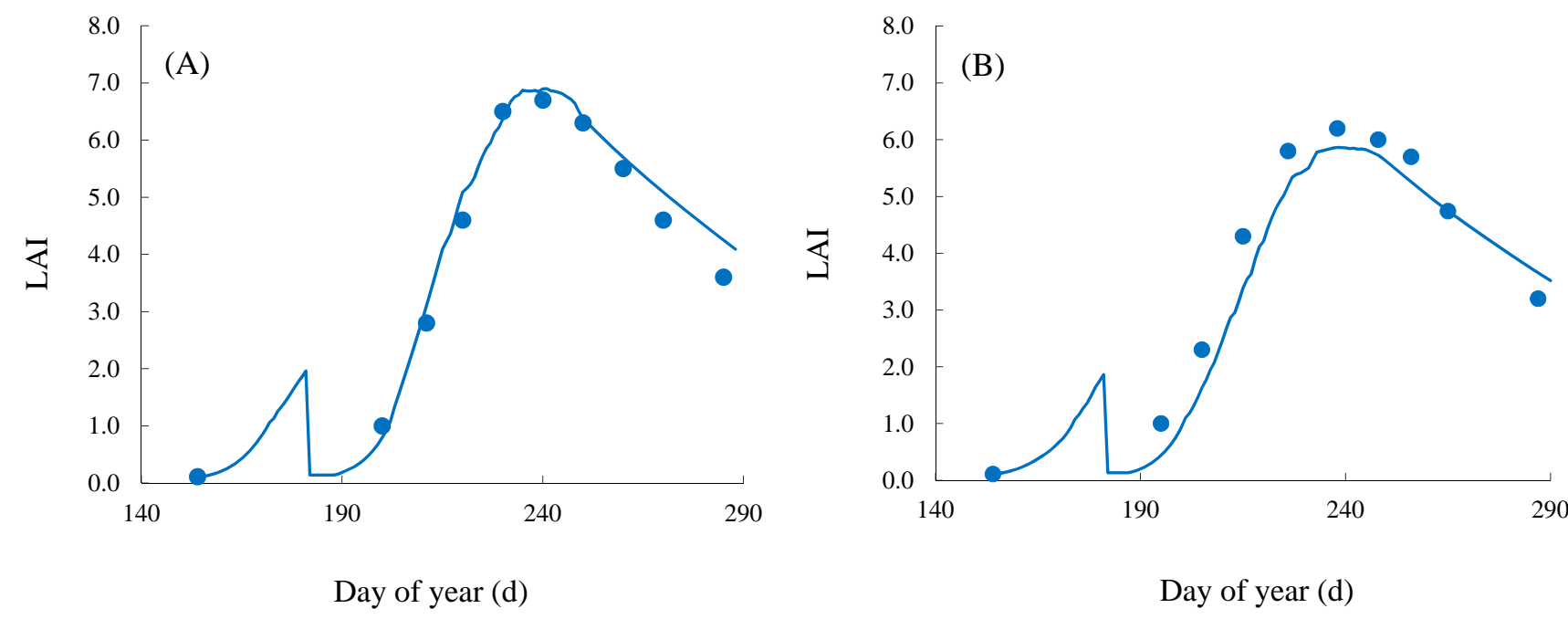

Figure 3 Simulated (solid line) and measured leaf area index (circle) over time in calibration period (A) and validation period (B) in Kunshan 
(A)

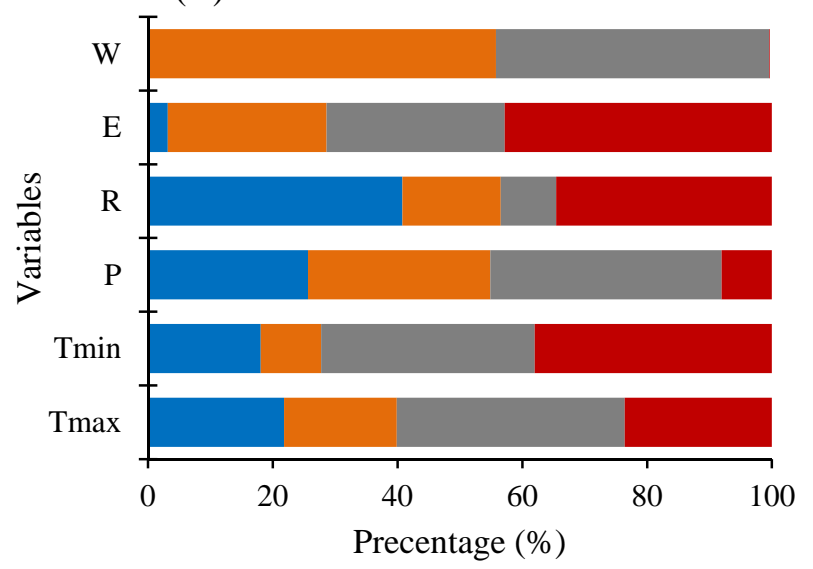

(C)

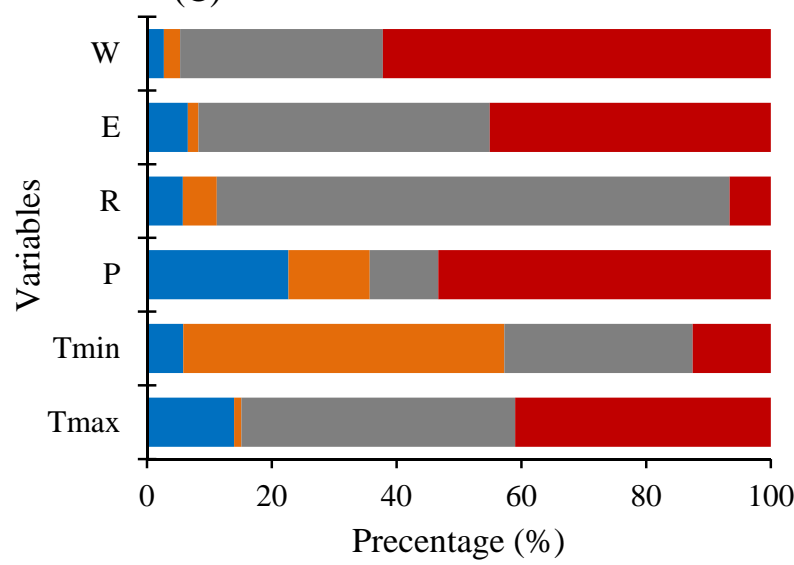

(B)

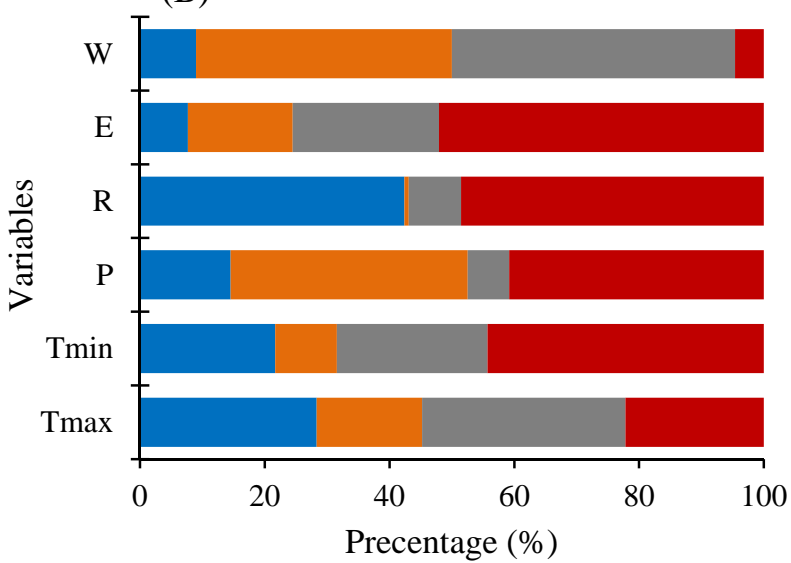

- BCC-CSM1.1(m)

GFDL-ESM2M

- HadGEM2-ES

- MIROC-ESM-CHEM

Figure 4 Weights of four GCMs for the six climate variables according to the BMA method in Kaifeng (A), Nanjing (B) and Kunshan (C) 

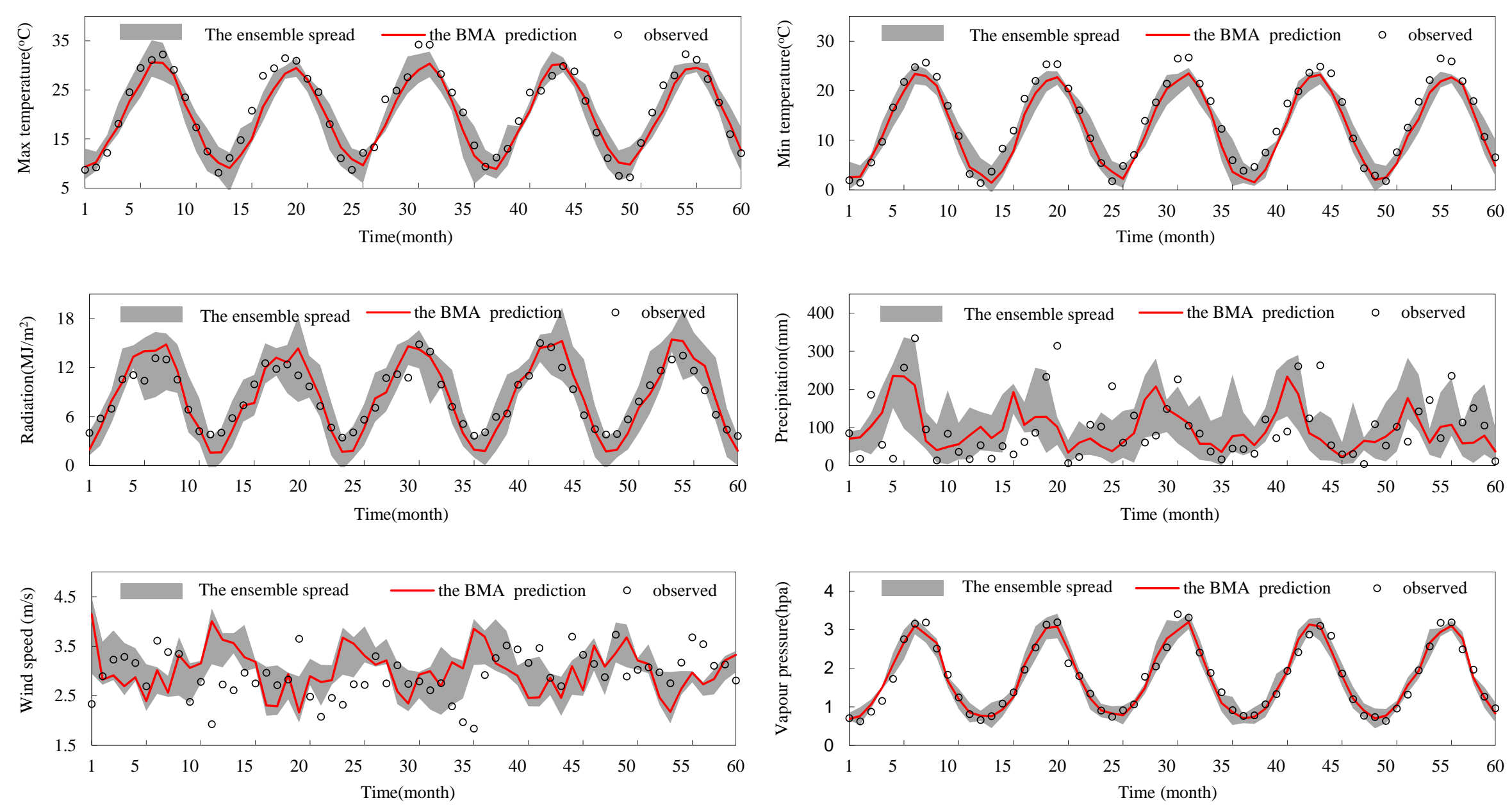

Figure 5 The BMA simulation results of six climatic variables for basin average during 2001-2000 

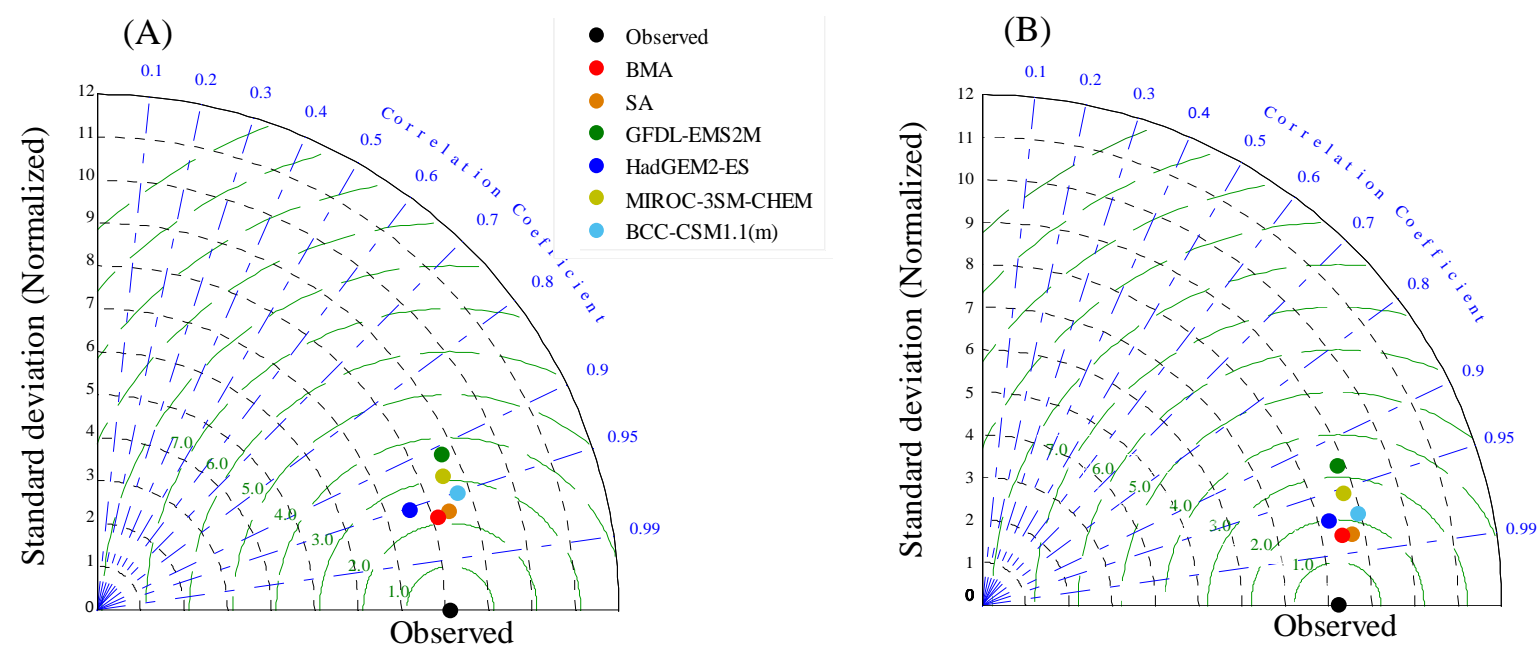

(C)

(D)
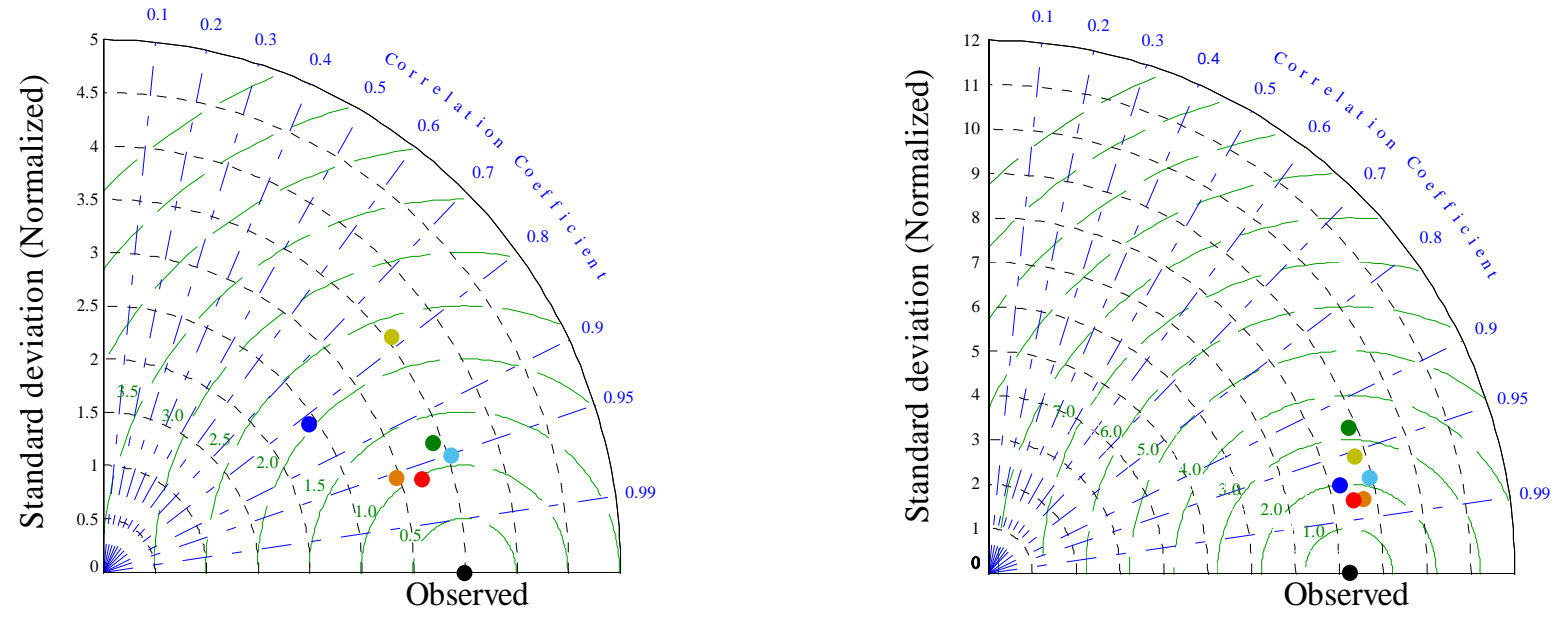

(E)

(F)
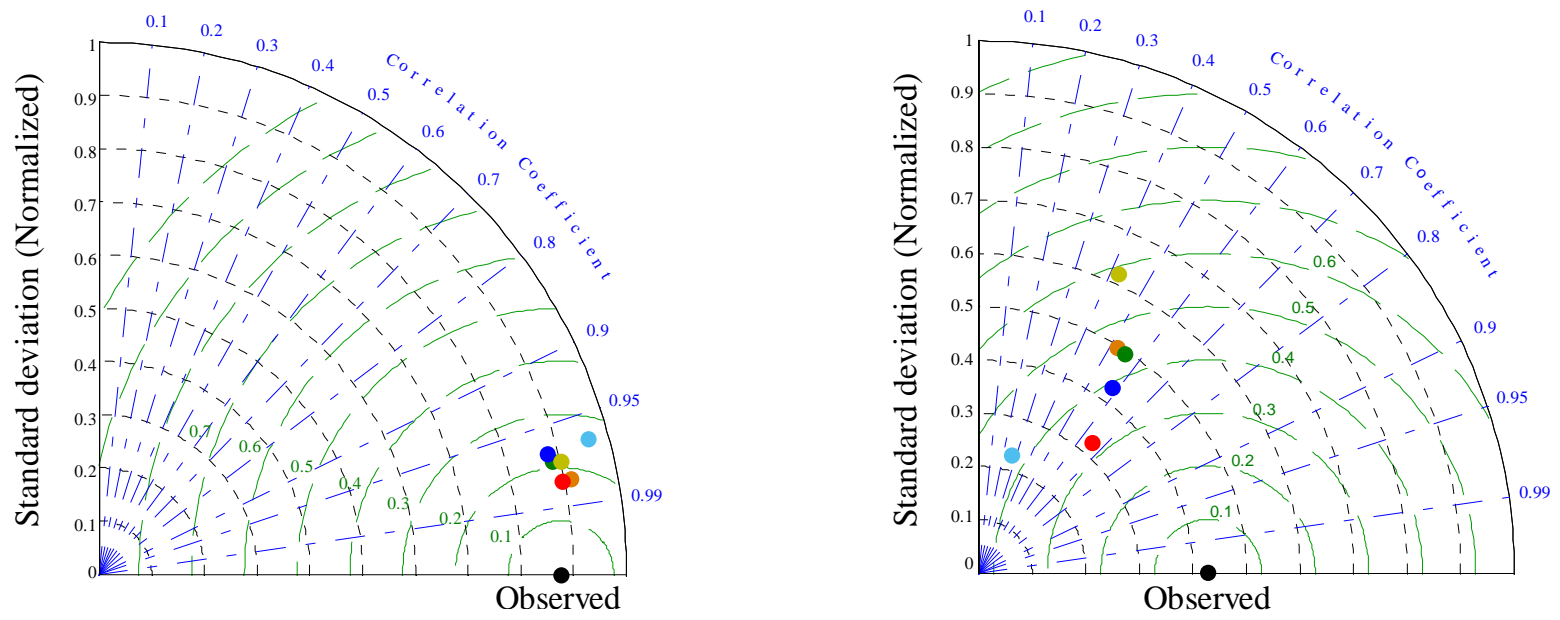

Figure 6 Taylor diagrams for projected (A) max temperature, (B) min temperature precipitation, (C) radiation, (D) precipitation, (E) vapor pressure, and (F) wind speed in Kunshan station evaluated against observed ones for 2001-2005. The Taylor diagrams compare actual observations with simulations by individual GCM model, the SA method as well as the BMA method, and summarize three metrics of the correlation (curved axis), the ratio of the standard deviations ( $x$ and y axes), and the RMSE (dashed line). The closer a point is to the observed data, the better the fit between observed and simulated data 
(A)

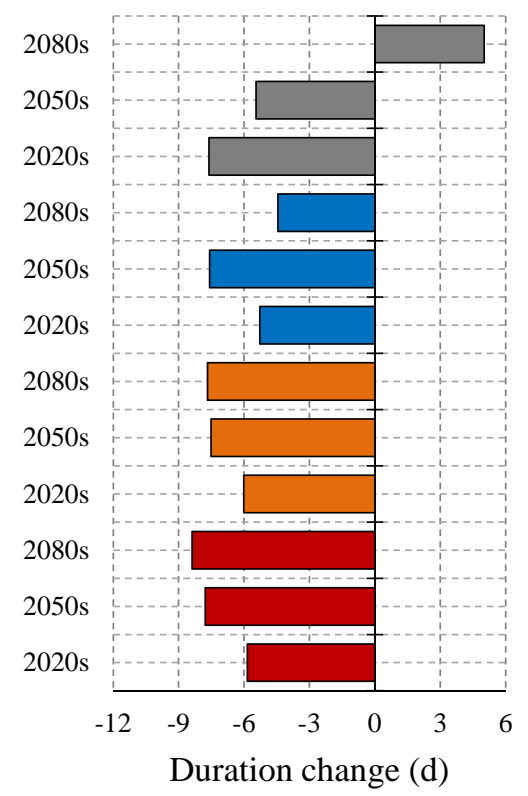

(B)

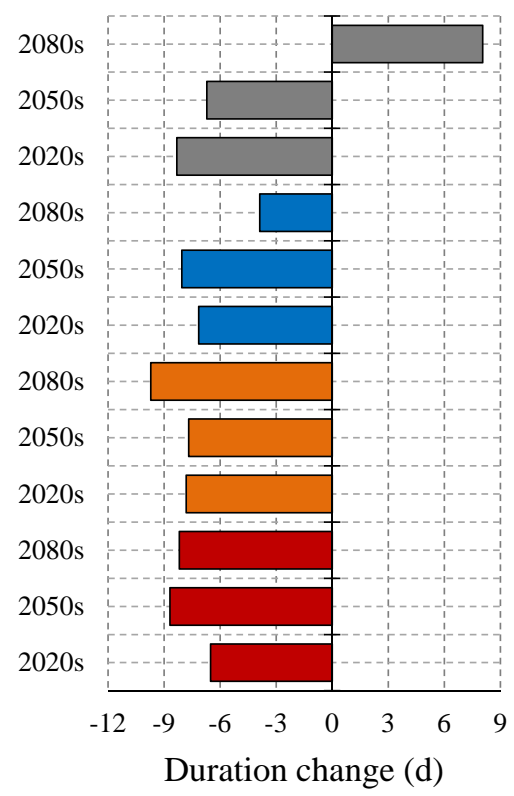

(C)

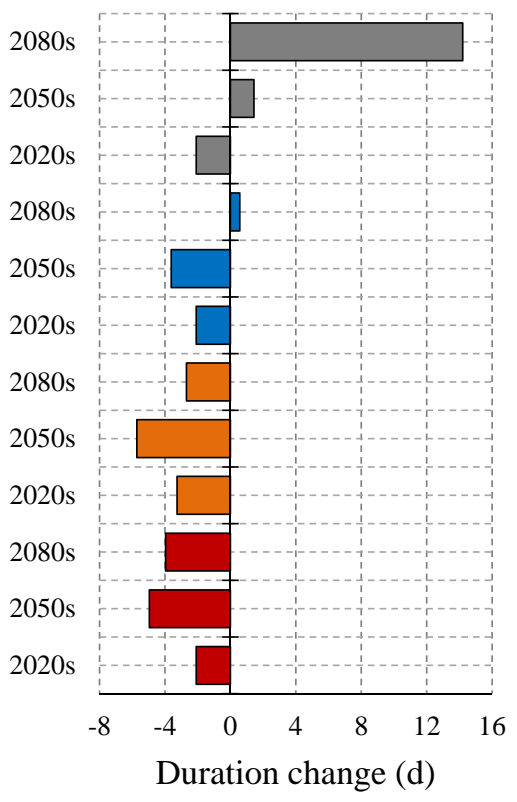

$\square \mathrm{RCP} 2.6 \quad \square \mathrm{RCP} 4.5 \quad \square \mathrm{RCP6.0} \quad \square \mathrm{RCP8.5}$

Figure 7 Changes of rice growth duration under future climate scenarios relative to the baseline in Kaifeng (A), Nanjing (B) and Kunshan (C) 

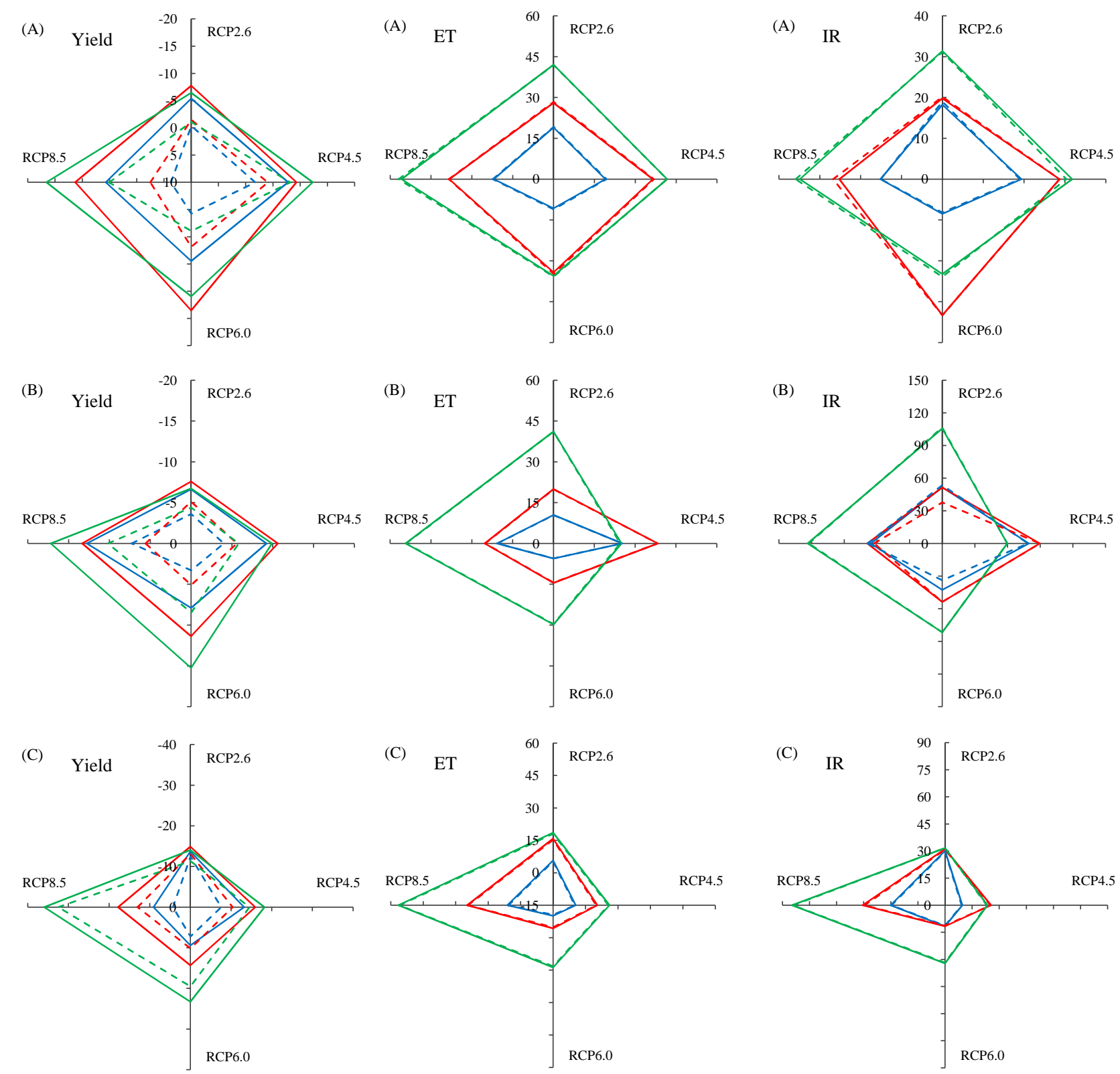

Figure 8 Changes of rice yield, ET and IR under future climate scenarios relative to the baseline in Kaifeng (A), Nanjing (B) and Kunshan (C) for 2020s (solid blue), 2050s (solid red) and 2080s (solid green). The related value was demonstrated with dashed line when $\mathrm{CO}_{2}$ fertilization effect was taken into consideration 

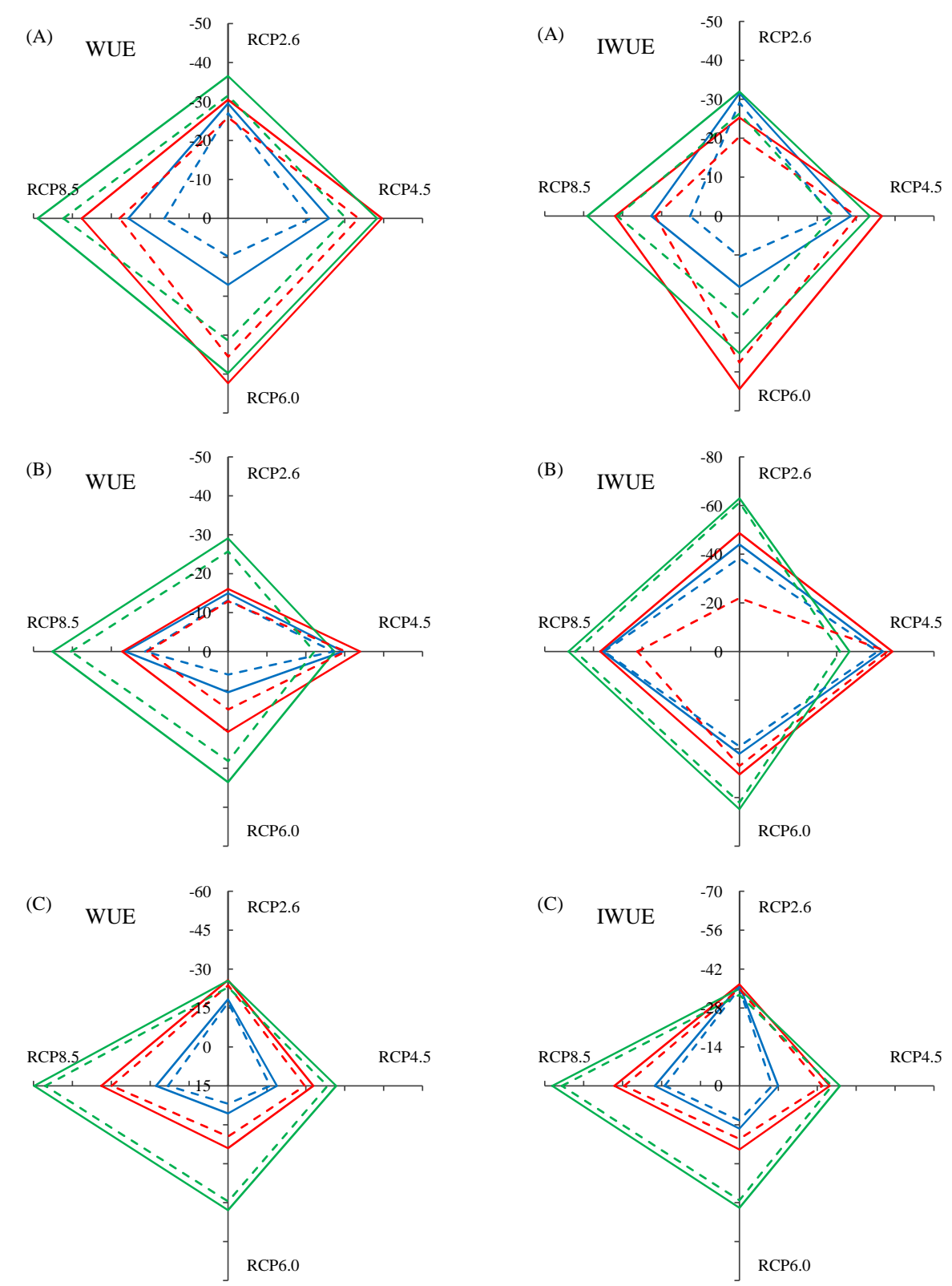

Figure 9 Same as Fig. 8, but for WUE and IWUE 

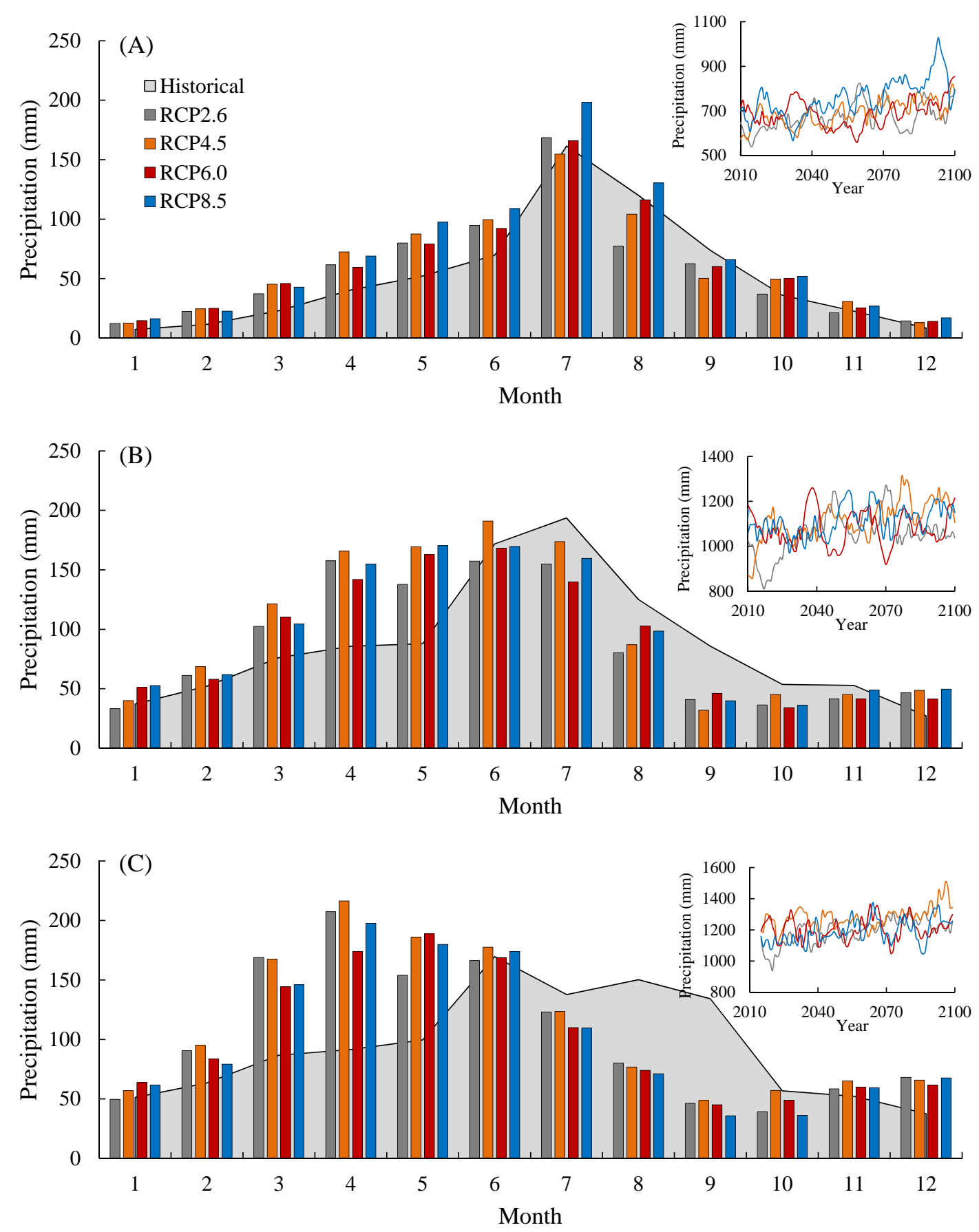

Figure 10 Monthly average precipitation of three experiment stations (Kaifeng (A), Nanjing (B) and Kunshan (C)) in 2080s under four scenarios. Histogram represent monthly mean precipitation of 4 scenarios, while gray territory represent historical monthly mean precipitation. The insert shows five years moving averaging of precipitation in 21st century under 4 scenarios 